\title{
Elastic Modulus, Thermal Expansion, and Pyrolysis Shrinkage of Norway Spruce Under High Temperature
}

\author{
Tito Adibaskoro (D*, Michalina Makowska, Aleksi Rinta-Paavola, and \\ Simo Hostikka, Department of Civil Engineering, Aalto University, \\ P.O. Box 12100, 00076 AALTO Aalto, Finland \\ Stefania Fortino, VTT Technical Research Centre of Finland Ltd, \\ P.O. Box 1000, 02044 VTT Espoo, Finland
}

Received: 28 August 2020/Accepted: 24 March 2021/Published online: 30 April 2021

\begin{abstract}
The orthotropic and temperature-dependent nature of the mechanical properties of wood is well recognized. However, past studies of mechanical properties at elevated temperatures are either limited to temperatures below $200{ }^{\circ} \mathrm{C}$ or focus only on the direction parallel to grain. The effect of time-dependent pyrolysis during measurement is often neglected. This paper presents a novel method for determining elastic modulus at high temperatures and thermal expansion coefficient in different orthotropic directions via Dynamic Mechanical-Thermal Analyser (DMTA). The method allows for drying, drying verification, and measurement in one chamber, eliminating the possibility of moisture reabsorption from ambient air. The repeatable measurements can be carried out in temperatures up to $325^{\circ} \mathrm{C}$, adequate for observing time-dependent pyrolysis during measurement. Results of the measurements of Norway Spruce provide data of its mechanical response at temperature range previously not explored widely, as well as in the orthotropic direction. Timedependent behaviour was observed in the thermal expansion and shrinkage experiment, where above $250^{\circ} \mathrm{C}$ the amount of shrinkage depends on heating rate. At such temperature, elastic moduli measurement also shows time dependence, where longer heating at certain temperature slightly increases the measured elastic modulus. Additionally, bilinear regression of the relationship between elastic moduli and temperature shows quantitatively good fit. Numerical simulation of the DMTA temperature history and wood chemical components mass losses show the onset of shrinkage and onset of hemicellulose mass loss occurring at around the same time, while decomposition of cellulose correlate with the sudden loss of elastic moduli.
\end{abstract}

Keywords: DMTA, Elastic moduli, Norway spruce, Pyrolysis, Shrinkage, Thermal expansion

\footnotetext{
*Correspondence should be addressed to: Tito Adibaskoro, E-mail: tito.adibaskoro@aalto.fi
} 


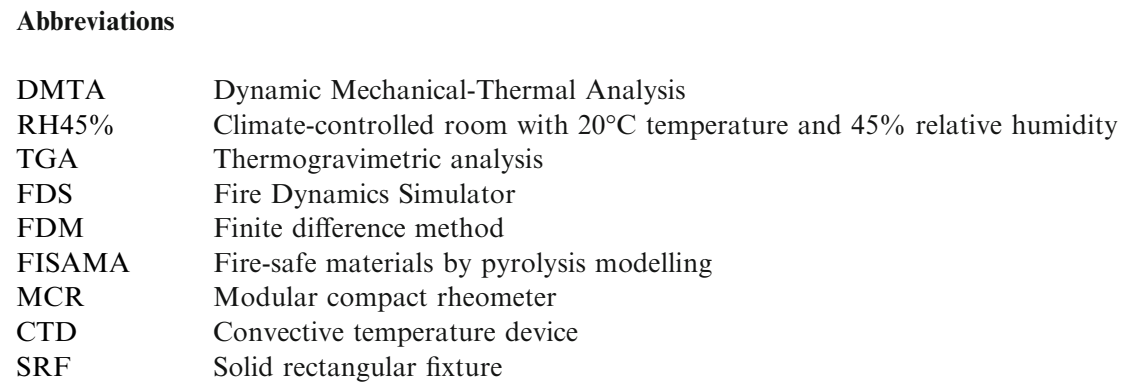

List of symbols

$\begin{array}{ll}\varepsilon & \text { Strain }(-) \\ \alpha & \text { Thermal expansion coefficient }\left(/{ }^{\circ} \mathrm{C}\right) \\ T & \text { Temperature }\left({ }^{\circ} \mathrm{C}\right) \\ t & \text { Time }(\mathrm{s}) \\ \rho & \text { Density }\left(\mathrm{kg} \mathrm{m}^{-3}\right) \\ c & \text { Specific heat capacity }\left(\mathrm{Jkg}^{-1} \mathrm{~K}^{-1}\right) \\ \kappa & \text { Thermal conductivity }\left(\mathrm{Wm}^{-1} \mathrm{~K}\right) \\ E & \text { Elastic modulus }(\mathrm{Pa}) \\ C & \text { Elastic modulus reduction rate }\left(\mathrm{Pa} \mathrm{K}^{-1}\right) \\ F & \text { Tensile force }(\mathrm{N})\end{array}$

\section{Introduction}

Wood is known for being anisotropic, with mechanical properties commonly identified in three orthogonal directions: radial $(\mathrm{R})$, tangential $(\mathrm{T})$, and longitudinal (L), as shown in Fig. 1. Knowing the mechanical properties in all three directions and at different moisture conditions is important for the detailed modelling of the mechanics of wooden structures. Additionally, modelling fire situations requires material properties at elevated temperatures. Values of the elastic modulus and tensile strength in the three orthogonal directions are reported in the literature [1, 2]. In many cases, the ratios between $\mathrm{L}$ and $\mathrm{R}$ or $\mathrm{T}$ are provided at room temper-

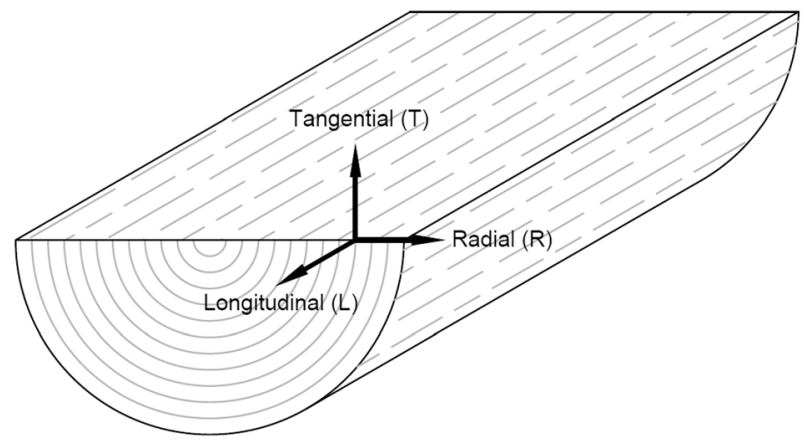

Figure 1. The orthotropic directions of wood. 
ature only, while the available high temperature data mostly covers only the L direction and up to $200^{\circ} \mathrm{C}$ to $275^{\circ} \mathrm{C}$ [3, 4]. Additionally, many studies only postulate the behaviour at higher temperatures. For example, there is no consensus on the shape of the relationship between the elastic moduli in the L direction and temperature above $200^{\circ} \mathrm{C}$ [4-9]. The curves for those relationships are sometimes developed using a different sample for each temperature, in which case the sampling uncertainty propagates to the obtained temperature dependence. For engineering purposes, the assumptions of linear strength and moduli reductions, reaching zero at $300^{\circ} \mathrm{C}$, are suggested for practitioners [10].

The sample cross-sections during the elastic moduli evaluation are typically greater than $10 \mathrm{~mm} \times 10 \mathrm{~mm}$ and up to $50 \mathrm{~mm} \times 50 \mathrm{~mm}$ [3]. The selection of proper sample size for experimental evaluation of the mechanical properties in the $\mathrm{R}$ and $\mathrm{T}$ directions is complicated. Increasing the sample size will lead to higher probability of localized alterations or imperfections in the mechanical properties, transferring the analysis from pure material scale towards real-life structures. On the other hand, the equipment optimized to studying wood in L direction may not be sensitive enough for the measurement in $\mathrm{R}$ and $\mathrm{T}$ directions, and the geometrical design of the equipment may not be suitable for vastly different sample sizes.

The effect of temperature on wood is well established in terms of mass loss (see e.g. [11-14]). However, seldom is it taken into account in the mechanical tests. One rare example is the study by Goodrich et al. [15], connecting compressive strength to Thermogravimetric Analysis (TGA). Some of the discrepancies between the reported changes in the elastic moduli in relation to increasing temperature could potentially be related to the differential temperature distribution within the sample. The heating rates and the level of pyrolysis are often not discussed in the context of an experimental parameter for the mechanical response in bulk. Considering the different rates of pyrolysis at various temperatures $[11,16]$, it is postulated that the size of the sample, as well as the time during which the sample remains at elevated temperature, should be parameters of the elastic moduli measurement.

The goal of this paper is to present an experimental methodology for the reliable estimation of defect-free clear wood mechanical properties at elevated temperatures by optimizing the sample size to ensure thermal equilibrium. The focus of this research is in evaluation of the mechanical behaviour of spruce in the $\mathrm{R}$ and $\mathrm{T}$ orientations at temperatures above $200^{\circ} \mathrm{C}$. The methodology tests one sample across the entire temperature range of $25^{\circ} \mathrm{C}$ to $325^{\circ} \mathrm{C}$, eliminating the effects of the differences between samples. The effect of thermal expansion and pyrolysis are closely investigated to explain observed behaviours.

\section{Methods Overview}

The research process presented hereby comprises parallel numerical analysis and experimental tests, with their relationship presented in Fig. 2. The whole method consists of interconnected analyses but can be categorized into the main part that is the DMTA experiment and two numerical simulations (Finite Difference Analy- 


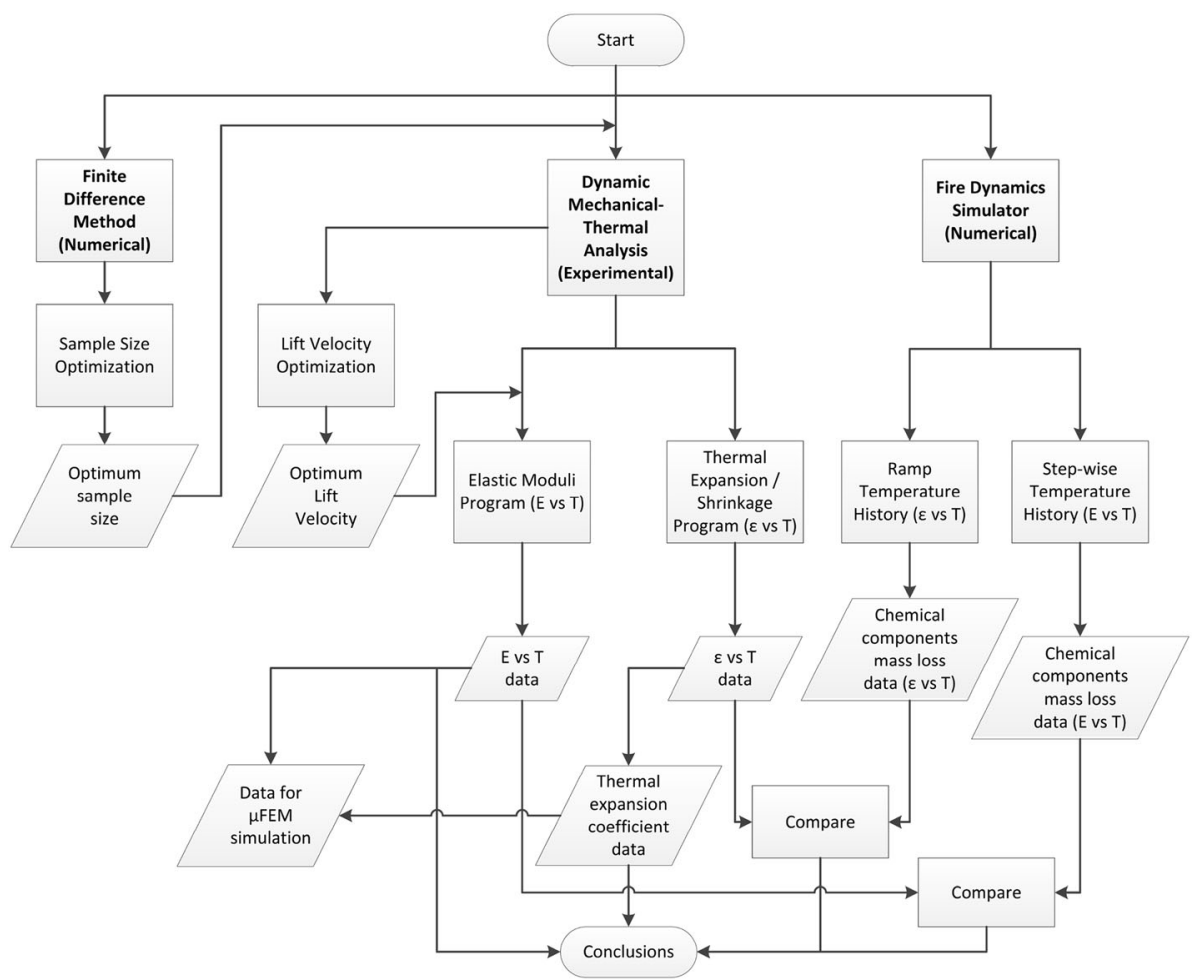

\section{Figure 2. Overall research process flowchart.}

sis and FDS (Fire Dynamics Simulator) analysis) which supports the experiment in terms of method optimisation and data interpretation. Besides supporting another study in simulating microscopic behaviour of wood under fire within the FISAMA project, the produced data can provide insight into the evolution of mechanical behaviour of wood under fire and offer material parameter input into simulations involving wood material and fire.

\section{Material and Sample}

\subsection{Test Material}

The experiment uses Norway Spruce (Picea abies) samples sourced in the same way as those in other related FISAMA (Fire-safe materials by pyrolysis modelling) project studies (see e.g. $[17,18]$ ). The data related to the mass loss during pyrolysis of the samples from the same batch is provided by Rinta-Paavola and Hostikka [18]. Tensile strength and elastic modulus of moisture-conditioned at $45 \% \mathrm{RH}$ and dry specimens were investigated previously by Kuronen [17] up to $250^{\circ} \mathrm{C}$. 
Kuronen initially planned to heat the samples of $20 \times 7 \mathrm{~mm}$ size with the heating rate of approximately $20^{\circ} \mathrm{C} / \mathrm{min}$, but noticed using the thermocouple that this approach does not result in achieving the set temperature inside of the sample. The final heating rate in Kuronen's study was approximately $6^{\circ} \mathrm{C} / \mathrm{min}$, but the scatter of the results was significantly high to be considered repeatable. It was postulated that the size of the sample, the differences between samples, moisture content and heating rate potentially contribute significantly to the scatter. The aim of hereby presented procedure was to minimize the effect of the mentioned parameters to the result of measurements.

\subsection{Sample Size Optimization}

The determination of sample size was closely tied together with the experimental equipment and procedure. Firstly, the sample needed to be thin enough to ensure uniform temperature distribution throughout, which is related to the heating rate. Secondly, the specimen dimension itself needed to consider the available space of the fixture and the convective oven. Thirdly, measurement of the specimen should be possible within $\pm 40 \mathrm{~N}$ of normal force (exceeding $\pm 50 \mathrm{~N}$ may damage the equipment). Finally, the specimen dimensions should be sensible for the laboratory technicians to produce.

After iterative trial-and-error process, we decided the most optimum specimen size was $4 \mathrm{~cm}$ long, $1 \mathrm{~cm}$ wide, and $1 \mathrm{~mm}$ thick. The small thickness allowed uniform temperature distribution within the specimen. A finite difference method (FDM) simulation assures minimum error due to temperature gradient. The problem simulated by our FDM model is similar to that in [19, 20], with experimental study across different specimens sizes (scales) in [21]. However, our simulation aimed to predict the resulting mechanical processes that lead to measurement errors. Additionally, we omitted irreversible effects, as the occurrence below $200^{\circ} \mathrm{C}$ and for such short period of time would be insignificant (see [16]).

For a typical $2^{\circ} \mathrm{C} / \mathrm{min}$ heating rate, finite difference simulation predicted only $0.02^{\circ} \mathrm{C}$ difference between minimum and maximum temperature, and $3.17 \%$ error in terms of thermal expansion evaluation (see "Appendix A"). Combined with length and width of $4 \mathrm{~cm}$ and $1 \mathrm{~cm}$, the sample fits comfortably with the specimen fixtures and within the available room inside the convective oven. The small sample thickness also allowed for visual inspection of wood defects.

Fabrication of such thin specimen resulted in some thickness variation $(0.72$ $\mathrm{mm}$ to $1.17 \mathrm{~mm}$ ). However, variations of thickness - and other dimensions - were taken into account in the data analysis. Our result repeatability suggested that this variation would not affect the result significantly. The use of the load controlled slow sawing devices was also considered and investigated for the purpose of sample preparation but ultimately decided against. The equipment requires lubricant such as water or glycol during the sawing process, which may influence the sample behaviour. 

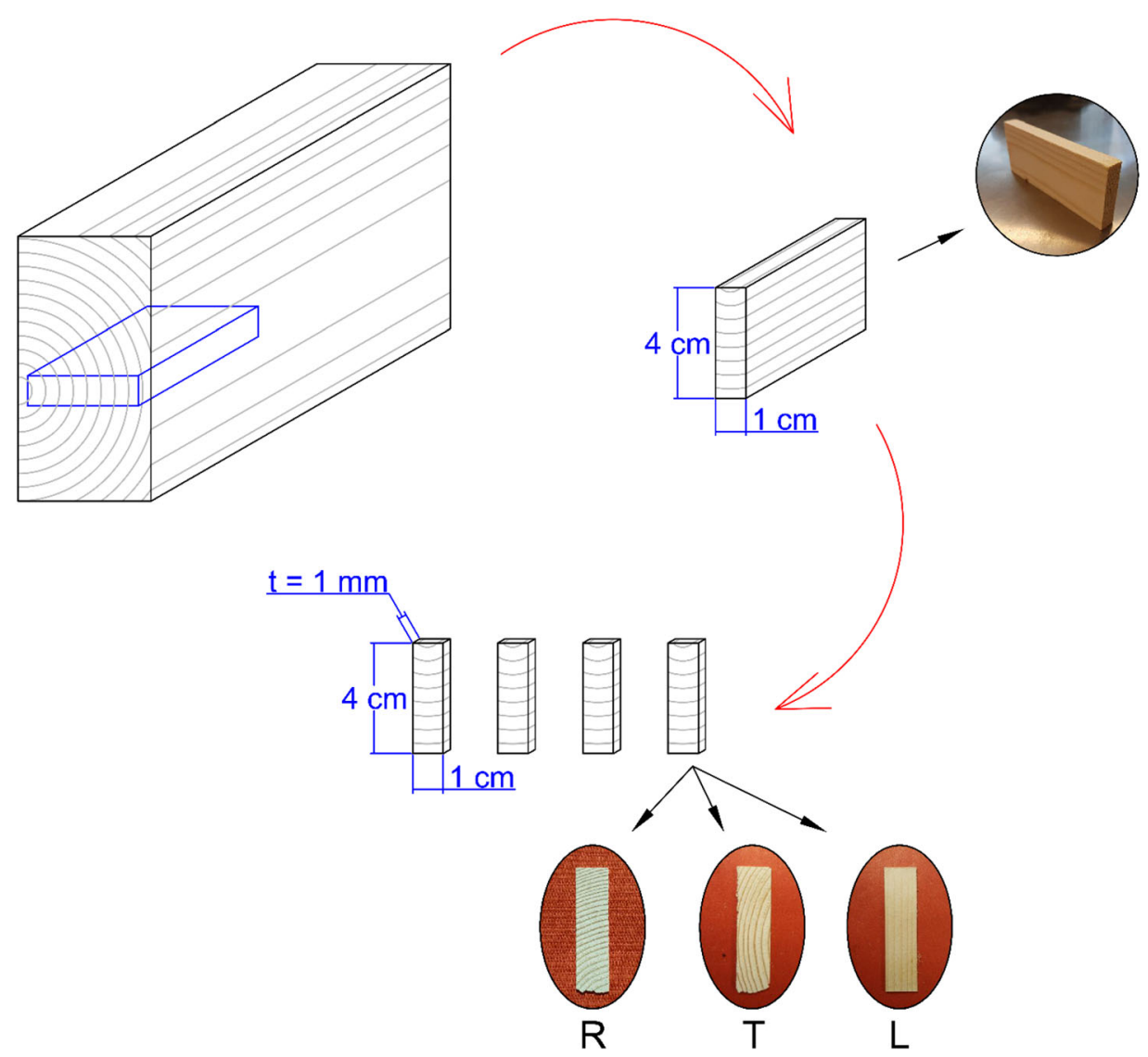

Figure 3. The schematic of sample fabrication: A wood beam is cut into $4 \mathrm{~cm} \times 1 \mathrm{~cm}$ cross sectioned blocks in such a way that accommodates the desired material direction to measure. The blocks are then further sliced into $1 \mathrm{~mm}$ thick pieces.

\subsection{Sample Preparation}

Large beams of Norway spruce were cut into small strips of around $1 \mathrm{~mm}$ thickness, $10 \mathrm{~mm}$ width and $40 \mathrm{~mm}$ length. The small sample dimensions allowed us to hand-pick defect-free specimens in R, T, and L directions. Figure 3 shows an illustration of specimen fabrication process. Section 4.3 explains the drying procedure carried out within the same oven as the experiment, otherwise the specimen would quickly reabsorb moisture upon contact with ambient air.

Initially, the plan included moisture conditioning of the thin samples in the RH45\% room for 21 days, but after the evaluation of the moisture content of such small samples it became apparent that this parameter is hard to control. Moving such small samples with high surface area to volume ratio between the climate room and measurement equipment reduces the expected $10 \%$ to $12 \%$ 
moisture content to $3 \%$ to $8 \%$ at the measurement room (testing in winter with low humidity). Additionally, drying also occurs continuously at significant rate during measurement due to high temperature and dry air supplied into the oven chamber. Therefore, we decided to measure dried specimens, which we can reliably prepare and maintain during measurements.

Two drying methods were explored: drying via convection oven at $105^{\circ} \mathrm{C}$ for $1 \mathrm{~h}$ and stream of nitrogen (AGA, 99.9\% purity) for $16 \mathrm{~h}$. The resulting mass loss were similar, however during transport and attachment process to the DMTA oven chamber significant moisture reabsorption occurred, which can be significantly observed in the form of shrinkage due to losing the reabsorbed moisture during measurement. The phenomenon was also shown by Rinta-Paavola and Hostikka [18] in the form of $2 \%$ mass drop due to moisture loss during the Thermogravimetric Analysis (TGA) below $100^{\circ} \mathrm{C}$.

Since our experiment measures displacement resulted from small strains, this shrinkage affects the result significantly. Therefore, we propose a drying method carried out inside the oven chamber itself, allowing for seamless transition between drying and measurement, eliminating specimen exposure to ambient air whatsoever. The following section explains the drying procedure and the technique to verify adequate drying in more detail.

\section{Experimental Method}

The following description of experimental method consists of two distinct measurements of quantity: thermal expansion and shrinkage (expansion/shrinkage program), and elastic modulus (moduli program). Figure 4 illustrates a simplified experimental procedure for both expansion/shrinkage program and moduli program. All procedures related to preparations and cooling down are exactly the same for both expansion/shrinkage and moduli program. The programs differ in terms of measurement procedures, which are the main parts of both programs. The expansion/shrinkage program measures a history of specimen extension/contraction due to thermal expansion and pyrolysis shrinkage given a certain temperature increase rate, while the moduli program measures elastic moduli at several temperature points, several times each, for every specimen.

\subsection{Equipment}

The equipment with the option to typically study Dynamic Mechanical Thermal Analysis of solids, namely MCR 302 with CTD 450 oven (Anton Paar, Germany) using the Solid Rectangular Fixture (SRF) (Fig. 5) was used for the studies after alterations to the typical DMTA testing protocol. Other necessary equipment included $99,9 \%$ purity nitrogen tank to avoid combustion, and dry air supply as part of the drying process, and liquid nitrogen for faster cooling after experiment. These three gasses were connected to the CDT oven one at a time, as illustrated in Fig. 6. 


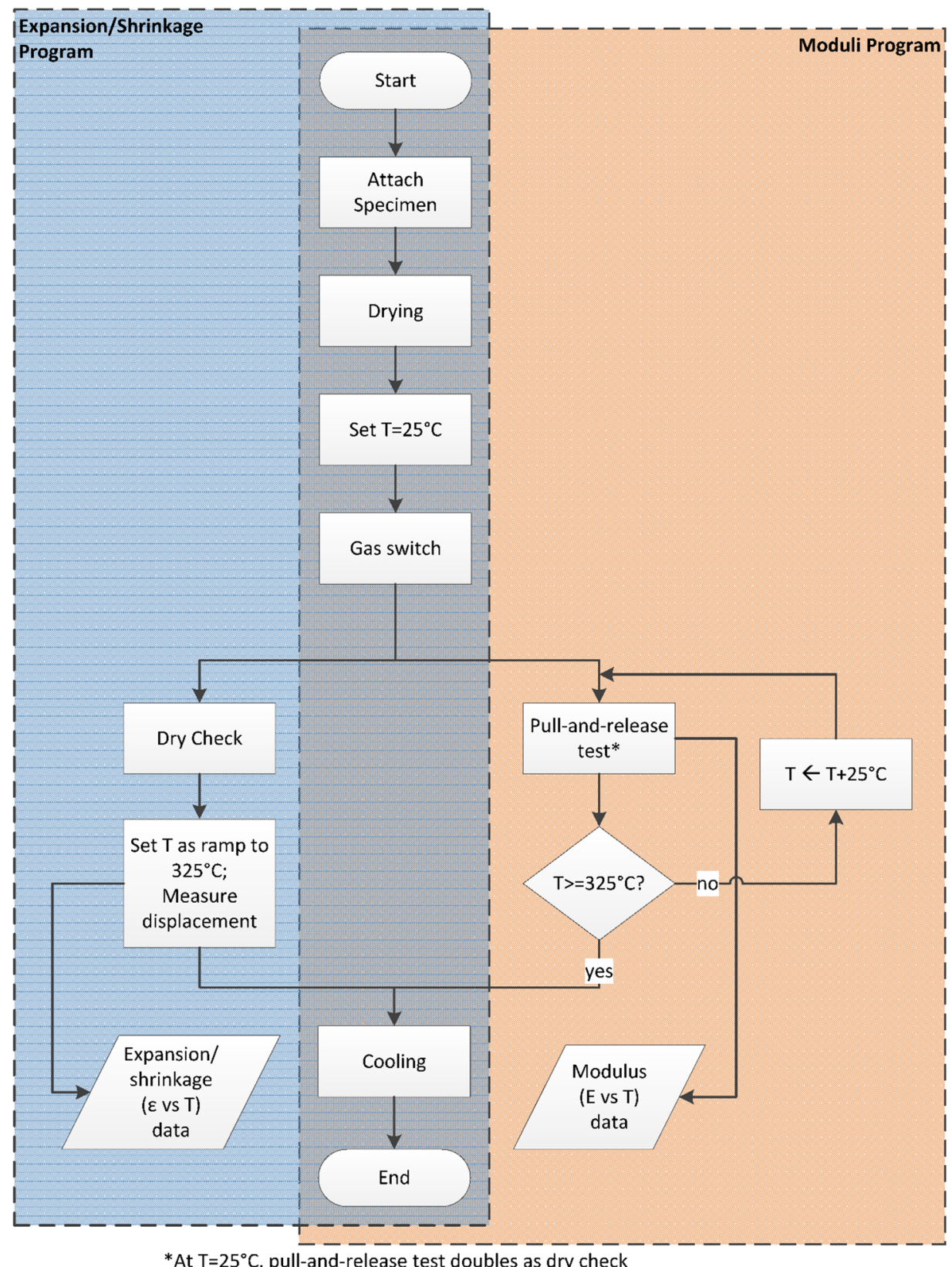

\section{Figure 4. Overall experimental procedure.}




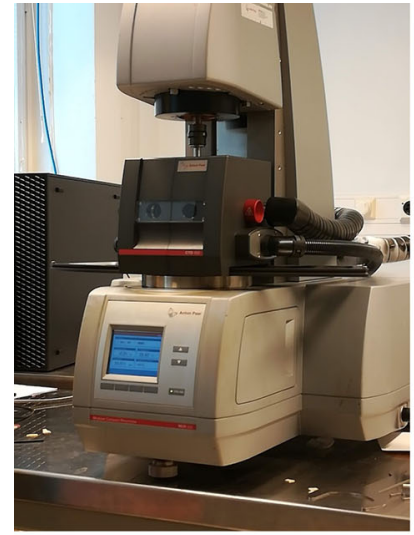

(a)

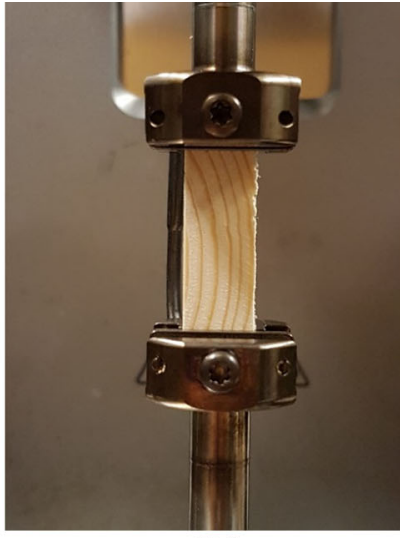

(b)

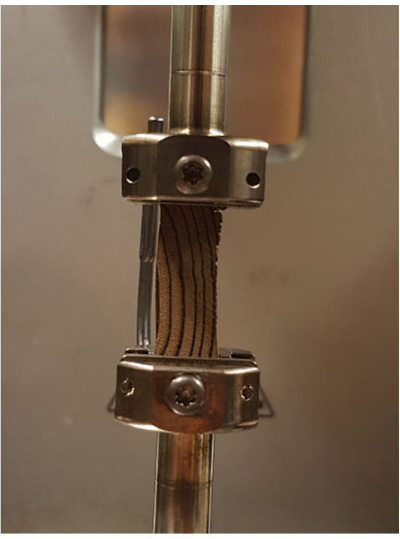

(c)

Figure 5. The equipment (a) and a sample assembled inside of a CTD on the SRF (b) before and (c) after the measurement.

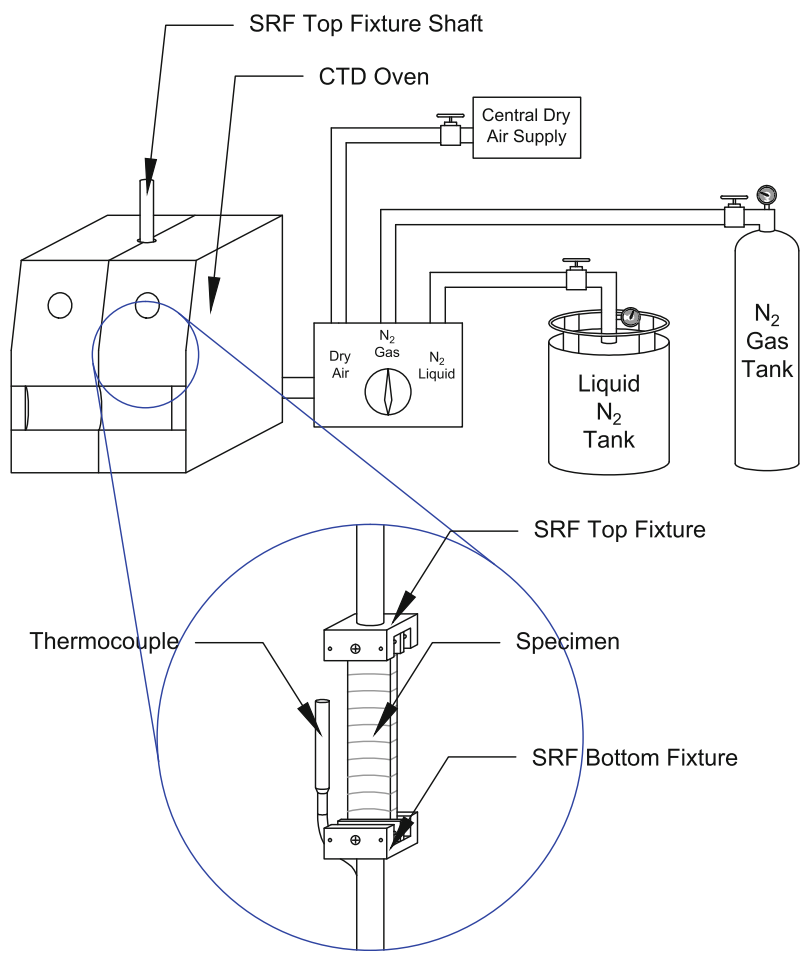

Figure 6. Experiment schematic: CTD Oven with SRF connected to dry air, $N_{2}$ gas, and liquid $N_{2}$ one at a time. 


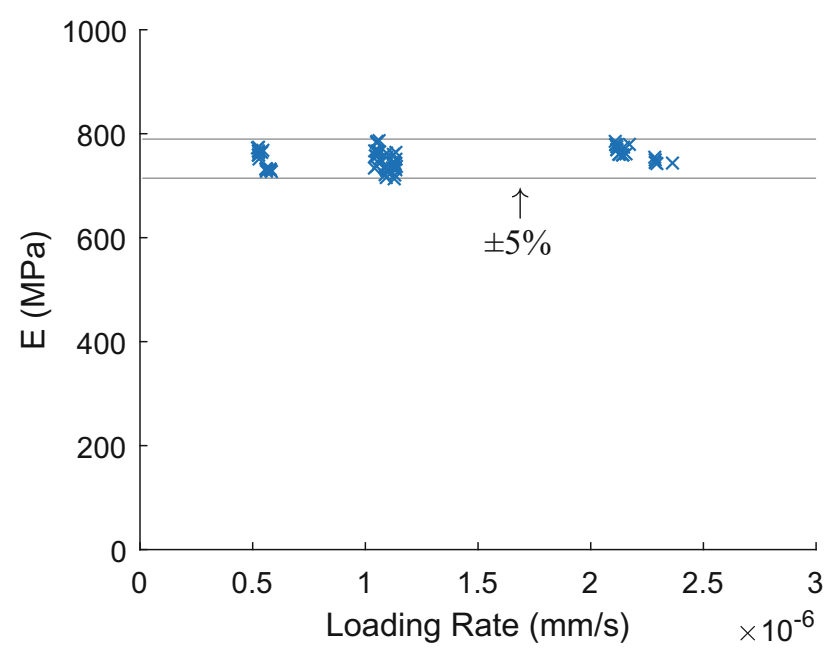

\section{Figure 7. The effect of shaft lift velocity on the established elastic modulus value at room temeprature.}

\subsection{Lift Velocity}

Primarily, it was established that within the lift velocity range of $0.5 \mu \mathrm{m} / \mathrm{s}$ to $2.5 \mu \mathrm{m} / \mathrm{s}$ the effect on the measured elastic moduli was less than $\pm 5 \%$ error at room temperature (see Fig. 7). In the case when the sample was initially dried to constant height in dry air, the differences in elastic moduli were even smaller. The use of extremely slow velocity caused samples to remain for longer period at elevated temperatures $\left(250^{\circ} \mathrm{C}+\right)$, leading to further progression of pyrolysis at the corresponding temperature, but the high velocity could cause damage to the sample during the measurements at high temperatures. As a result, the optimal lift velocity in this case was chosen as $\mathrm{v}=1.5 \mu \mathrm{m} / \mathrm{s}$. However, whether the velocity at pyrolysis temperatures affects the elastic moduli result significantly remains to be determined and is encouraged for further studies.

\subsection{Thermal Expansion/Shrinkage Program}

The expansion/shrinkage program consists of specimen drying and expansion/ shrinkage measurement. Figure 10 shows the history of displacement and temperature throughout time. After attaching specimen to the fixture and closing the oven, the experiment proceeds with three major procedures: drying, measurement, and cooling.

As mentioned before, drying the sample before measurement is not possible, as the thin specimen absorbs moisture in a matter of seconds when exposed to ambient air. Therefore, drying the specimen is carried out inside the oven chamber by exposing the specimen to the dry air at the rate of $850 \mathrm{Nl} / \mathrm{h}$ and elevated temperature of $50^{\circ} \mathrm{C}$. During the drying process, the shrinkage of the sample is observed. The end of the drying process is established at the point in which the sample no 
longer changes its dimensions. We established that $30 \mathrm{~min}$ of exposure to dry air at the temperature of $50^{\circ} \mathrm{C}$ (with additional time of heating up and cooling down) guarantees sufficient drying. A small tensile load of $0.9 \mathrm{~N}$ is applied during the whole process in order to avoid compression, which may cause buckling and damage the equipment. Additionally, by maintaining a small tension, specimen failure can be detected from its sudden absence, which then triggers a shut-down procedure to avoid equipment damage.

After the drying process and cooling oven down to $25^{\circ} \mathrm{C}$, the dry air supplied to the oven is switched to nitrogen gas of $99.9 \%$ purity with flow rate of $500 \mathrm{Nl} /$ h. Assuming the nitrogen gas carries no moisture is reasonable, necessary in the dry check procedure. During the switch, constant tension of $0.9 \mathrm{~N}$ still applies.

To check whether drying is sufficient, a simple "pull and release" test is carried out. This test is in fact the same as the main part of elastic moduli test. By pulling and releasing at a constant rate, the specimen is deemed sufficiently dry only if the load-displacement curve stays in the same path instead of drifting to the direction of negative displacement value. The pull and release test procedure is explained in more detail in Sect. 4.4. During dry check, the maximum $2 \mathrm{~N}$ load was applied to the sample and the displacement monitored. If the load-displacement curve stays on a single line, the sample was deemed sufficiently dry. Figure 8a and b show comparison between failed and successful dry check via pull-and-release test.

After the specimen is considered dry, the main part of the program begins: expansion and shrinkage measurement. The small constant tension of $0.9 \mathrm{~N}$ resumes, while temperature is increased at a constant rate. Displacement is then monitored, from which expansion/shrinkage strain can be calculated. Other necessary quantities are specimen's width, thickness, and free-hanging length, which are measured before the experiment.

Table 1 lists the specimen names, their material orientations, and the applied heating rates. The additional so-called "fast" heating rate aims to study the effect
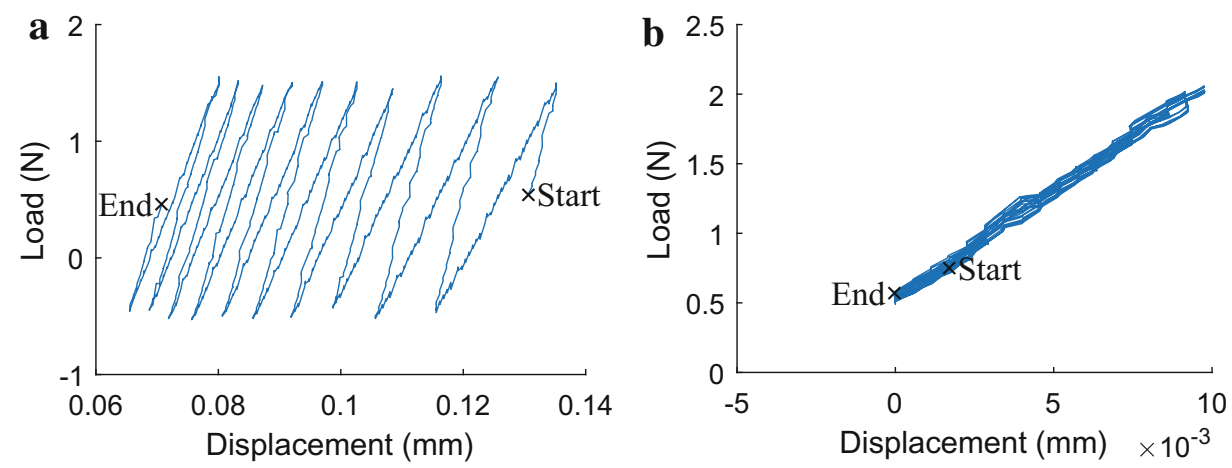

Figure 8. Examples of dry check; unsuccessful drying (a) shows loaddisplalcement curve drifting to the left-hand side when specimen is pulled and released as sample continues to shrink during the measurement, while successful drying (b) shows load-displacement curve going back and forth at the same location. 


\section{Table 1}

The Heating Rate Used for the Determination of Expansion

\section{Coefficients}

\begin{tabular}{llll}
\hline & & \multicolumn{2}{c}{ Heating rate $\left({ }^{\circ} \mathrm{C} / \mathrm{min}\right)$} \\
\cline { 3 - 4 } Orientation & Code & $<200^{\circ} \mathrm{C}$ & $>200^{\circ} \mathrm{C}$ \\
\hline $\mathrm{R}$ & SR1 & 7 & 1 \\
$\mathrm{R}$ & SR2 & 2 & 2 \\
$\mathrm{R}$ & SRfast & See Fig. 9 & 2 \\
$\mathrm{~T}$ & ST2a & 2 & 2 \\
$\mathrm{~T}$ & ST2b & 2 & 5 \\
$\mathrm{~T}$ & ST5 & 5 & 7 \\
$\mathrm{~T}$ & ST7 & 7 & 2 \\
$\mathrm{~L}$ & SL2a & 2 & 2 \\
$\mathrm{~L}$ & SL2b & 2 & \\
\hline
\end{tabular}

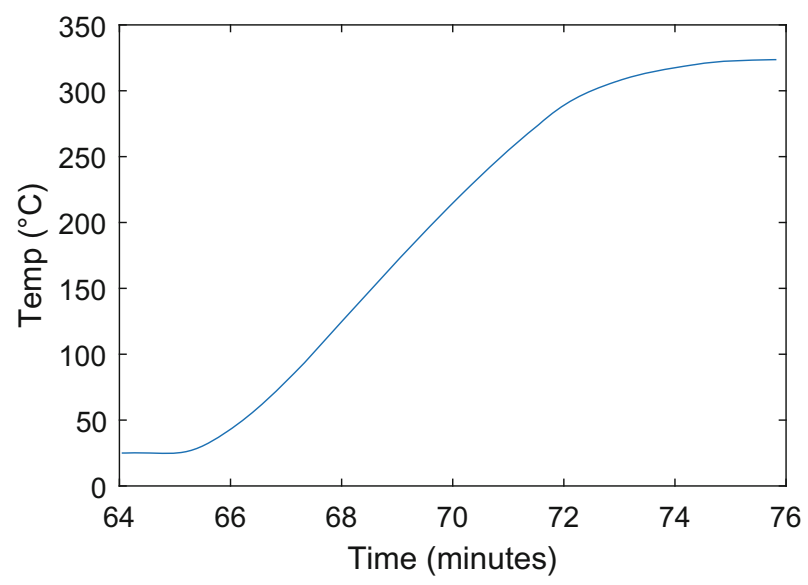

Figure 9. Temperature history of "fast" heating.

of high heating rate to the progression of pyrolysis shrinkage. The oven applied such heating rate by trying to reach $325^{\circ} \mathrm{C}$ as fast as possible, averaging at $25.38^{\circ} \mathrm{C} / \mathrm{min}$ (see Fig. 9). The experimental data for the thermal expansion/shrinkage program is included in [22].

The choices of heating rates are optimized towards slightly different purposes. SR1, SR2, and SRfast are aimed towards FDS modelling of pyrolysis reactions by simulating the realised temperature history within the CTD oven during experiments. $\mathrm{R}$ experiments are chosen as the resulting strain histories are the most linear. SR 1 features $7^{\circ} \mathrm{C} / \mathrm{min}$ and $1{ }^{\circ} \mathrm{C} / \mathrm{min}$ heating rates due to high possibility of running out of nitrogen if the experiment applies $1^{\circ} \mathrm{C} / \mathrm{min}$ since the beginning. On the other hand, specimens ST2a, ST2b, ST5, and ST7 are aimed towards result 


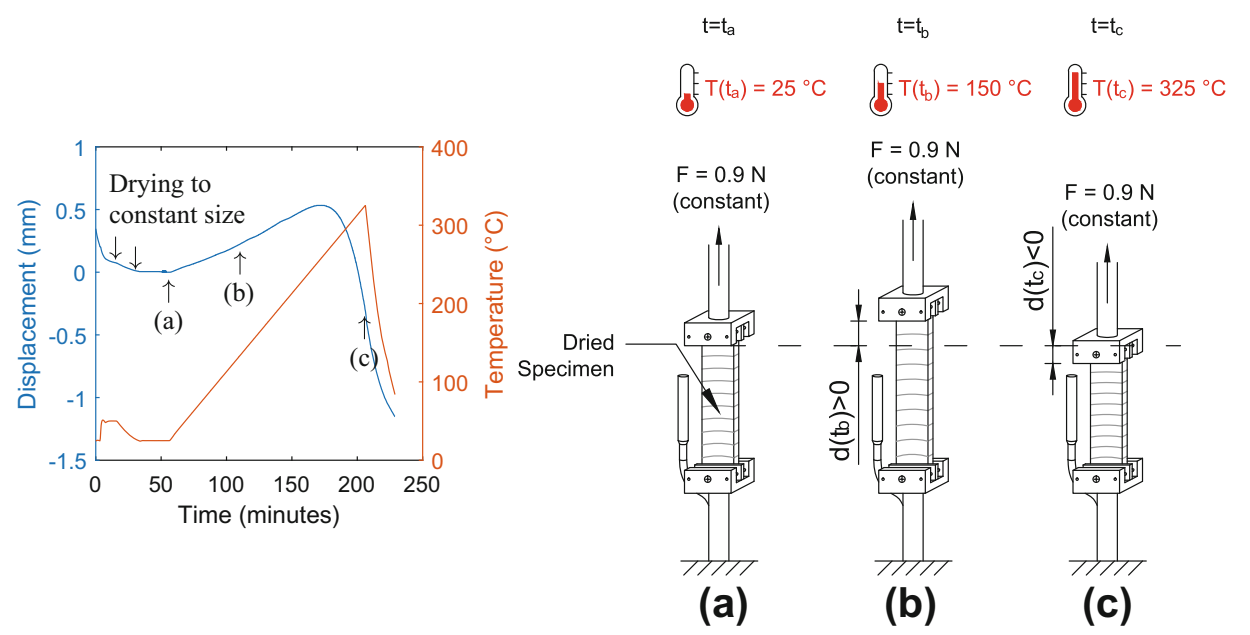

\begin{abstract}
Figure 10. Displacement and temperature history throughout the thermal expansion coefficient program (left) and illustration of key time points (right): (a) just before heating up; (b) extension due to thermal expansion; (c) net shrinkage due to pyrolysis.
\end{abstract}

replication. As will be explained in Sect. 6.1, an odd pattern emerged from the thermal expansion strain vs oven temperature plot for $\mathrm{T}$ specimens. Variation of heating rate can determine whether the pattern is time-dependent. Lastly, L specimens are incredibly difficult to conduct, as attempts at measurements might have already exceeded the capability of the equipment. Having constant $2^{\circ} \mathrm{C} / \mathrm{min}$ at allowed the measurement to reach the target temperature of $325^{\circ} \mathrm{C}$ without the specimens breaking or slipping from the fixture clamps.

Figure 10a shows a typical temperature and displacement history of the sample undergoing the program. Three key time points during measurement mark distinct states of the specimen: (a) dried before heating up, (b) extension from thermal expansion, and (c) net shrinkage due to pyrolysis. These three points are illustrated in Fig. 10b.

Cooling procedure immediately follows upon the completion of the measurement. Gas supply is switched from regular nitrogen gas to liquid nitrogen, providing cooling while still preventing combustion. The oven chamber can be opened only when the thermocouple indicates oven temperature below $30^{\circ} \mathrm{C}$ to prevent heat-striking the equipment.

\title{
4.4. Moduli Program
}

The main goal of the moduli program is to measure elastic modulus of the specimen several times at a certain temperature by repeatedly increasing and decreasing the applied tensile force. By comparing the change of tensile force to the change of displacement, elastic modulus can be extracted. Consequently, unlike the expansion coefficient program, the moduli program holds temperature at certain 
point throughout a set of pull-and-release cycles. Temperature increases a certain amount only in between sets.

The measurement is conducted between $25^{\circ} \mathrm{C}$ and $325^{\circ} \mathrm{C}$ with step-wise temperature increase of $25^{\circ} \mathrm{C}$. A series of 9 pull-release cycles is attempted at set temperature or for the period of $10 \mathrm{~min}$, whichever trigger is reached first. Peak pull tops at $2 \mathrm{~N}$ of tensile force, while maximum release is set at $0.5 \mathrm{~N}$. In between, the pull or release process occurs at a displacement-controlled rate of $1.5 \mu \mathrm{m} / \mathrm{s}$. Additionally, as a safety precaution, if the sample fails (tensile force drops to $0 \mathrm{~N}$ ), the measurement aborts. Note that while the measurement procedure differs, drying and cooling procedures that respectively precedes and follow after measurement are the same as those described in Sect. 4.3.

Additionally, the pull-and-release cycles double as time-dependent-deformation detector. The first pull-and-release cycle (executed at $25^{\circ} \mathrm{C}$ ) doubles as dry check, detecting any shrinkage due to still-ongoing drying. At temperatures below $200^{\circ} \mathrm{C}$, the cycles are able to detect any creep behaviour should there be any. At temperatures of $250^{\circ} \mathrm{C}$ and higher, pyrolysis shrinkage is expected to be the dominant source of time-dependent deformation. In fact, the pyrolysis shrinkage occurred in way which resembled creep behaviour during the release halves of the pull-and-release cycles. This phenomena is discussed further in Sect. 6.2.

Figure 11 shows the typical displacement and temperature history of measurement via the moduli program for one specimen. A more close-up snapshot of the history is shown in Fig. 12 (left), with three key points marked in the pull-release cycle. These three points in time are illustrated in Fig. 12 (right), showing the specimen extending at peak pull compared to the state at maximum release. Since the difference in tensile force is given, the measured difference in displacement relative to a constant datum determines the elastic modulus. Table 2 shows the naming of the specimens, while experimental data for the moduli program is included in [22].

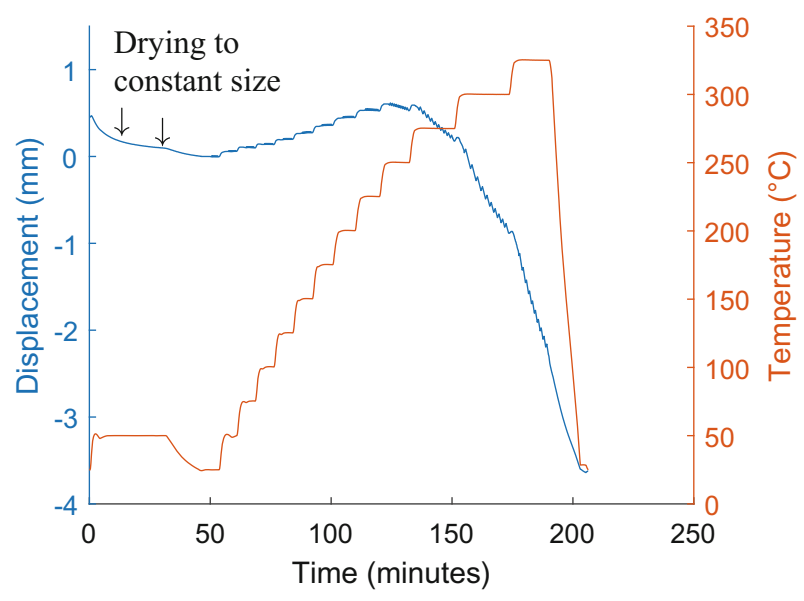

Figure 11. Displacement and temperature history throughout the moduli program. 


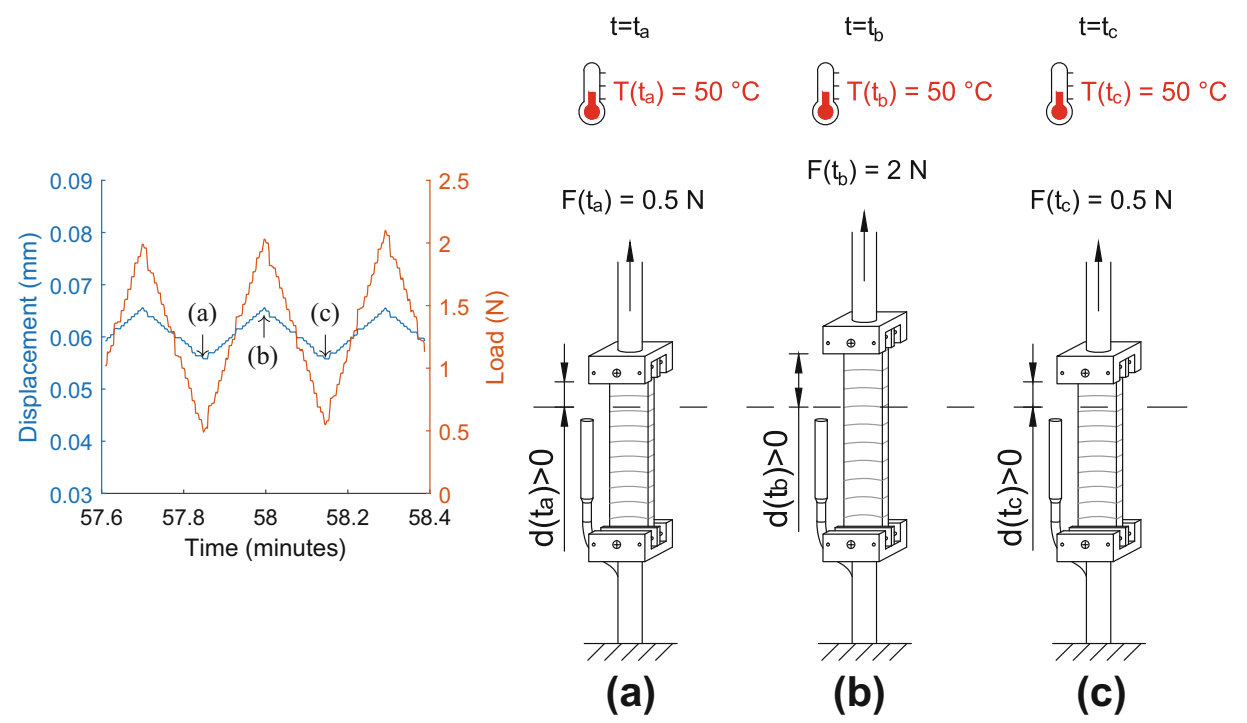

Figure 12. Displacement and temperature history throughout one cycle of pull-and-release of the moduli program (left) and illustration of key time points (right): (a) at maximum release; (b) at maximum pull; (c) at maximum release on the next cycle.

\section{Table 2}

\section{E vs T Specimen Naming}

\begin{tabular}{ll}
\hline $\mathrm{R}$ & ER1, ER2, ER3 \\
$\mathrm{T}$ & ET1, ET2, ET3 \\
$\mathrm{L}$ & EL1 \\
\hline
\end{tabular}

\section{Numerical Methods}

Two numerical methods are conducted in this study. Firstly, Finite Difference Method (FDM) simulation predicts temperature distribution throughout the specimen thickness and the resulting measurement error of the specimen. Secondly, Fire Dynamics Simulator (FDS) simulation outputs decomposition history of wood primary components under temperature histories realized in the DMTA experiments. The following describes the FDS simulation, while "Appendix A" explains the FDM simulation in more detail.

The FDS model involves zero-dimensional simulations of mass loss of pyrolyzing Norway spruce specimens under the temperature histories from DMTA experiments. The primary component distribution of the spruce wood in simulations is assumed identical to that reported by Sjöström [28]. The simulations assume a 
completely dry wood with zero water content. The kinetic parameters and the char yields for the pyrolysis reactions are estimated from Thermogravimetric Analysis (TGA) experiments in the work of Rinta-Paavola and Hostikka [18], including the description of the assumed pyrolysis reaction in the numerical model.

The pyrolytic decomposition of wood in the simulations is described by the parallel reactions model, i.e. each main component (extractives, hemicellulose, cellulose, lignin) pyrolyzes through their respective reactions, each with their individual kinetic parameters (frequency factor $A$, activation energy $E_{a}$, reaction order $n$ ) and char yields. The residual ash is inert. Pyrolysis reactions follow the typical reaction order (Arrhenius) model. As the TGA experiments are carried out under a flow of pure nitrogen, the reaction model does not consider oxidation. The DMTA experiment was conducted under nitrogen flow as well, with the heating rates similar to those used in TGA, therefore the developed models are considered the perfect tool to study compositional changes in material during the DMTA experiments.

The first experiment is the E vs T Radial \#2 (specimen ER2) (see Fig. 18) with step-wise heating (see Table 2). The second and third specimens are thermal expansion/shrinkage experiment for radial direction with heating rates of 7 to $1{ }^{\circ} \mathrm{C} / \mathrm{min}$ (SR7-1), and as fast as possible (SRFast) (see Table 1). As the simulations are zero-dimensional, the wood specimen following the temperature program precisely and non-existent temperature gradients within the specimen are assumed.

\section{Results and Discussion}

\subsection{Thermal Expansion Coefficient}

The expansion coefficient measurements at various heating rates suggest that the expansion follows an almost linear trend until up to $200^{\circ} \mathrm{C}$. Until that temperature thermal expansion in the sample is independent on the heating rate. Above $200^{\circ} \mathrm{C}$ the shrinkage is observed and the rate of shrinkage depends on the heating rate. This was incorporated into some of our measurements, in which the initial heating rate would be $7^{\circ} / \mathrm{min}$ below $200^{\circ} \mathrm{C}$ and for example $1{ }^{\circ} \mathrm{C} / \mathrm{min}$ above it. Such alteration of testing program allows for lower consumption of inert gases. Figure 13a shows the expansion and shrinkage strains of $\mathrm{R}$ specimens with various heating rates.

The strain history is then approximated by a 2 nd order polynomial regression (see Fig. 14), which first derivative gives thermal expansion coefficient.

$$
\begin{aligned}
& \varepsilon_{\text {thermal expansion }}=1.85 \times 10^{-7} T^{2}+5.21 \times 10^{-5} T-0.00134 \\
& \Rightarrow \alpha=\frac{\partial \varepsilon_{\text {thermal expansion }}}{\partial T}=3.7 \times 10^{-7} T+5.21 \times 10^{-5}
\end{aligned}
$$

Other thermal expansions are expressed as: 


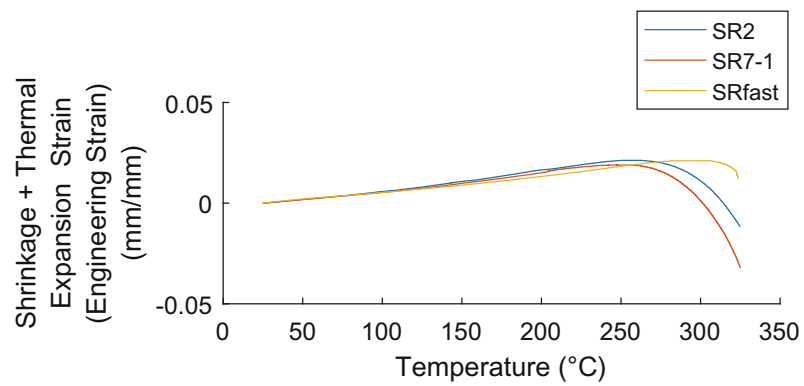

(a)

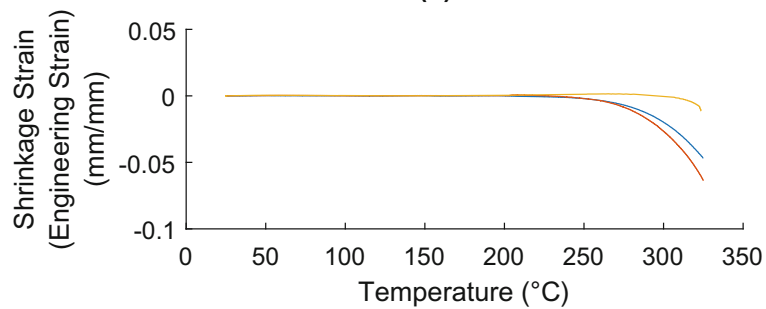

(b)

Figure 13. The effect of the heating rate on the shape of the sample in holder: (a) total strain directly calculated from displacement reading; (b) shrinkage strain only, by subtracting thermal expansion from total strain.

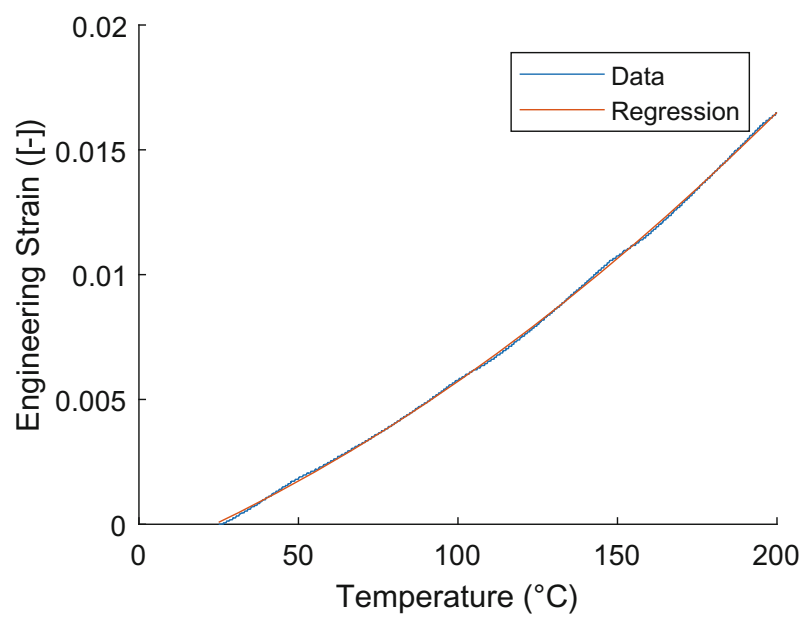

Figure 14. Engineering strain regression in $\mathbf{R}$ direction. 


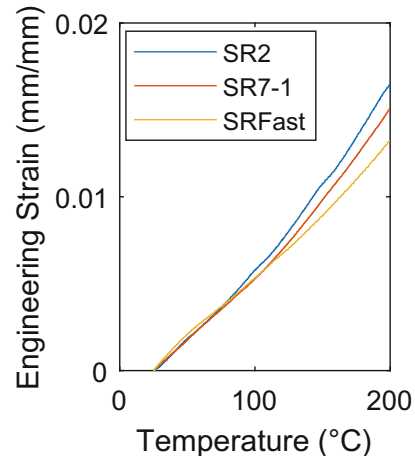

(a)

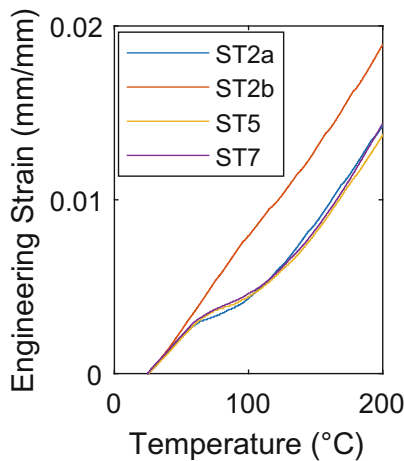

(b)

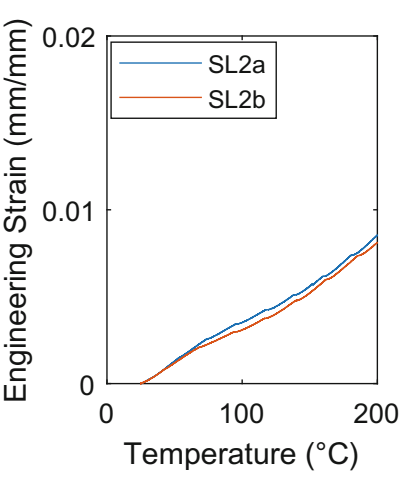

(c)

Figure 15. Thermal expansion experimental data in $R(a), T(b)$, and $L$ (c) directions.

\section{Table 3}

Thermal Expansion Coefficients Determined from the Measurements from $25^{\circ} \mathrm{C}$ to $50^{\circ} \mathrm{C}$

\begin{tabular}{|c|c|c|c|c|c|c|c|}
\hline \multirow[b]{2}{*}{ Direction } & \multirow[b]{2}{*}{ Code } & \multirow{2}{*}{$\begin{array}{l}\text { Heating rate } \\
\left({ }^{\circ} \mathrm{C} / \mathrm{min}\right)\end{array}$} & \multirow[b]{2}{*}{ A } & \multirow[b]{2}{*}{ B } & \multicolumn{3}{|c|}{$\alpha\left(10^{-6}\right)$} \\
\hline & & & & & $\mathrm{T}=25^{\circ} \mathrm{C}$ & $\mathrm{T}=37.5^{\circ} \mathrm{C}$ & $\mathrm{T}=50^{\circ} \mathrm{C}$ \\
\hline $\mathrm{R}$ & SR2 & 2 & $9.99 \mathrm{E}-07$ & $3.98 \mathrm{E}-05$ & 64.8 & 77.3 & 89.7 \\
\hline $\mathrm{R}$ & SR1 & $7-1$ & $-3.19 \mathrm{E}-07$ & $8.09 \mathrm{E}-05$ & 73.0 & 69.0 & 65.0 \\
\hline $\mathrm{R}$ & SRfast & fast & $-9.13 \mathrm{E}-07$ & $1.18 \mathrm{E}-04$ & 95.3 & 83.9 & 72.5 \\
\hline $\mathrm{T}$ & ST2a & 2 & $6.76 \mathrm{E}-07$ & $6.26 \mathrm{E}-05$ & 79.5 & 87.9 & 96.4 \\
\hline $\mathrm{T}$ & $\mathrm{ST} 2 \mathrm{~b}^{\mathrm{a}}$ & 2 & $1.33 \mathrm{E}-06$ & $5.02 \mathrm{E}-05$ & 83.6 & 100.2 & 116.9 \\
\hline $\mathrm{T}$ & ST5 & 5 & $5.21 \mathrm{E}-07$ & $6.26 \mathrm{E}-05$ & 75.6 & 82.1 & 88.6 \\
\hline $\mathrm{T}$ & ST7 & 7 & $-2.00 \mathrm{E}-07$ & $9.29 \mathrm{E}-05$ & 87.9 & 85.4 & 82.9 \\
\hline $\mathrm{L}$ & SL2a & 2 & $1.35 \mathrm{E}-06$ & $1.66 \mathrm{E}-06$ & 35.3 & 52.2 & 69.0 \\
\hline $\mathrm{L}$ & SL2b & 2 & $7.41 \mathrm{E}-07$ & $2.10 \mathrm{E}-05$ & 39.5 & 48.8 & 58.0 \\
\hline
\end{tabular}




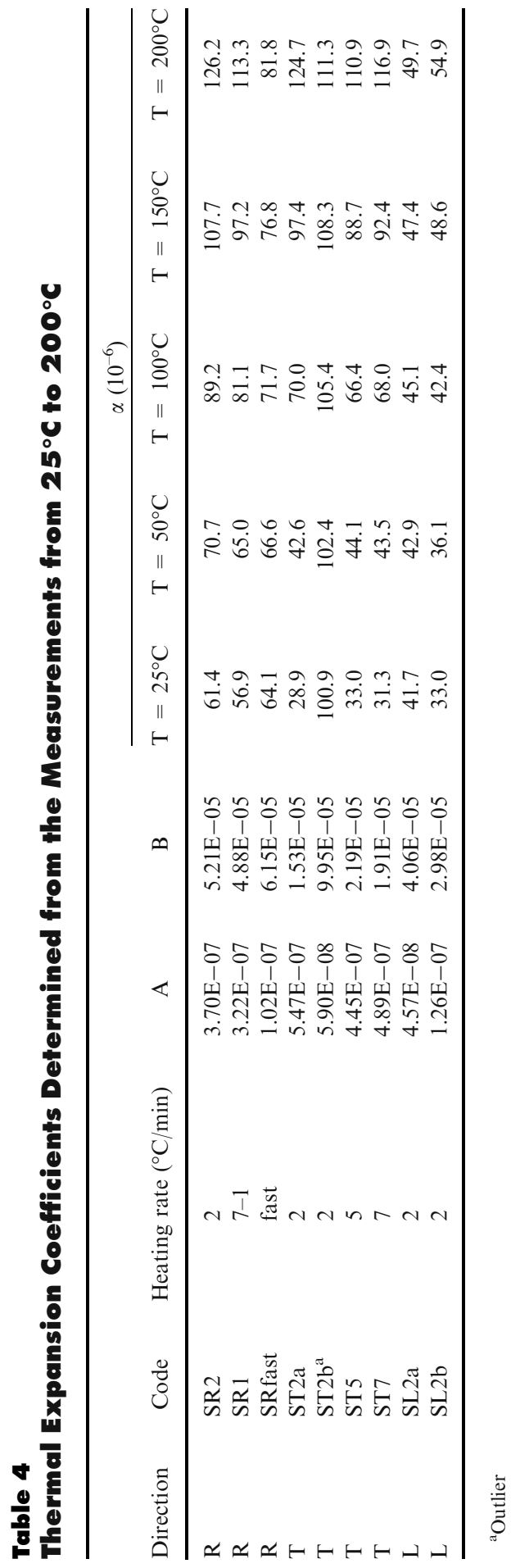




$$
\alpha=A T+B
$$

With $A$ and $B$ shown in Table 4

For each strain history, two regressions are carried out at different temperature ranges. The first regression approximates the strain history from $25^{\circ} \mathrm{C}$ to $50^{\circ} \mathrm{C}$, so that the results can be compared to existing reports found in literature [29]. The second regression takes into account the data from $25^{\circ} \mathrm{C}$ to $200^{\circ} \mathrm{C}$, since hereby study is aimed towards high temperature. Figure 15 shows the experimental data of thermal expansion strain vs temperature for $\mathrm{R}, \mathrm{T}$, and $\mathrm{L}$ directions, which raw data can be accessed in [22]. Tables 3 and 4 present the thermal expansion coefficients from the former and latter temperature ranges respectively. Additionally, by knowing the thermal expansion coefficient, thermal expansion can be subtracted from total strain history, resulting in pyrolysis shrinkage strain history only, as shown in Fig. 13b.

Table 3 presents the thermal expansion coefficients from strain history range of $25^{\circ} \mathrm{C}$ to $50^{\circ} \mathrm{C}$. Compared to previous reports (see [29]), we observe similar pattern of thermal expansion coefficients in $\mathrm{R}$ direction being comparable but on average slightly lower than the coefficients in $\mathrm{T}$ direction. Additionally, the thermal expansion coefficients in $\mathrm{L}$ direction is significantly lower than those in $\mathrm{R}$ and $\mathrm{T}$.

Results of the thermal expansion coefficient calculation from $25^{\circ} \mathrm{C}$ to $200{ }^{\circ} \mathrm{C}$ is presented in Table 4. Compared to the former results, we see a significant difference most profoundly found in the $\mathrm{T}$ direction. Looking closer into the data, we observed a significantly nonlinear strain history for $\mathrm{T}$ direction, and $\mathrm{L}$ direction at lesser extent, above $50^{\circ} \mathrm{C}$. Amongst each material direction, the nonlinearity is replicated by every sample ${ }^{1}$ via closely-matching strain-temperature curves despite the variety in heating rates. Therefore, time-dependent processes such as unfinished drying, creep, or pyrolysis can be ruled out as the cause of this behaviour.

\subsection{Elastic Moduli}

The described moduli program successfully measured elastic moduli values with good repeatability for temperatures low enough to have negligible pyrolysis shrinkage, which threshold for the timescale of the proposed measurement method is around 200 to $250^{\circ} \mathrm{C}$. Below this temperature, no time-dependent behaviour was detected. In contrast, above this temperature threshold, irreversible pyrolysis process manifest itself to an extent that is significantly observable from the measurement data in at least three aspects. First of all, the presence of pyrolysis shrinkage necessitates additional data processing method to correctly extract elastic moduli values from the raw measurements (Figs. 16, 17), which results are the main goal of the moduli program and presented in Figs. 18, 19, 20. Additionally, close observation at the equipment's measurement history and the processed data

\footnotetext{
${ }^{1}$ ST2b did not exhibit the same behaviour. ST2a, ST5, and ST7 having very similar strain-temperature curves lead us to conclude ST2b to be an outlier for reasons we are unable to identify. Such circumstance would be impossible to identify had we not conducted our measurements above $50^{\circ} \mathrm{C}$, as results from below $50^{\circ} \mathrm{C}$ suggests reasonably similar result.
} 
revealed a creep-like behaviour and increase of elastic moduli over time at a given temperature.

Firstly, the pyrolysis shrinkage affects the elastic moduli readings. As described in the experimental method of the moduli program (Sect. 4.4), the procedure involves increasing (pull) and decreasing (release) the amount of tensile load while monitoring the change of top fixture position. At high temperatures, the presence of pyrolysis shrinkage affects this result, signified by pull and release measurements showing substantial difference in elastic moduli readings. The extent of this shrinkage is demonstrated by the thermal expansion and shrinkage experiment discussed in the previous subsection, more specifically Fig. 13. This alone could have been the source of the error in the past measurements. The correction factor, considering the shrinkage, was used to recalculate the obtained load-displacement curved and determine the elastic modulus from shrinkage corrected data. "Appendix B" details the shrinkage correction procedure, while Fig. 17 shows the result of the procedure for specimen ET3.

Secondly, the load-displacement curves of the pull-release cycles at high temperature reminisce the curve of creep during release stage of the program, as shown in Fig. 16a. The applied load was always between between $0.5 \mathrm{~N}$ and $2 \mathrm{~N}$ (tensile pull followed by release) at each temperature. At room temperatures, approximately 6 cycles can fit within a minute. However, above the pyrolysis onset temperature, the shrinkage causes the increasing normal force on the sample resulting in the slower return to the value of $0.5 \mathrm{~N}$. Since pyrolysis at an isothermal condition progresses in an asymptotic fashion [11], supported by an overall constantlydecreasing shrinkage rate occurring at a certain constant temperature shown in Fig. 11, it can be deduced that at a given temperature pyrolysis shrinkage occurs

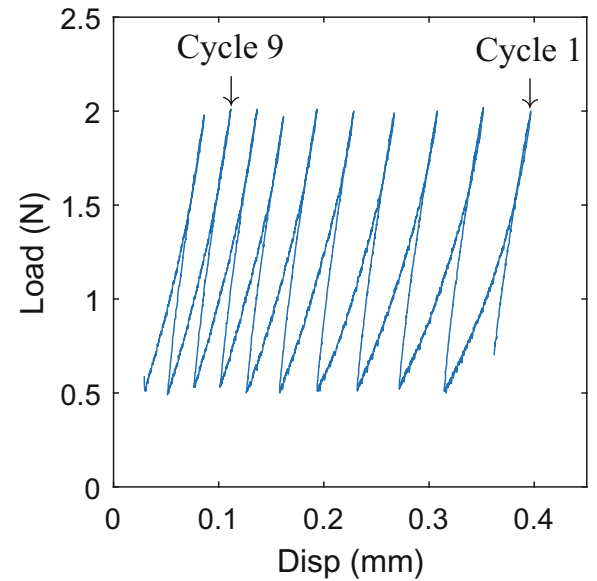

(a)

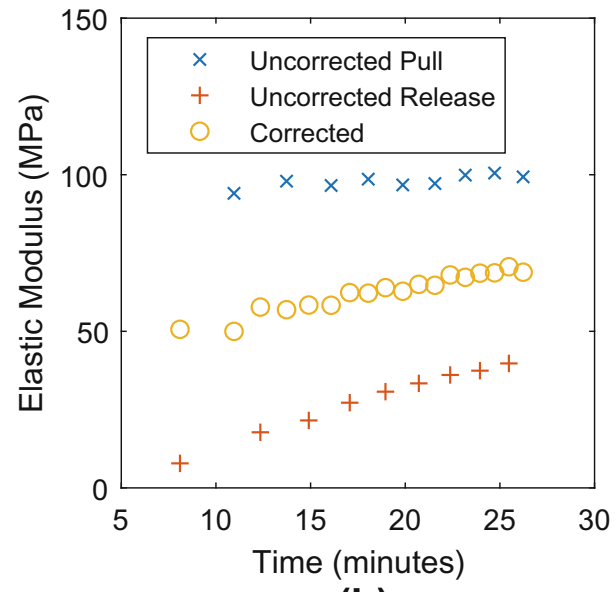

(b)

Figure 16. Load-displacement measurement (a) and elastic moduli measurement with/without correction (b) of specimen ER3 at $300^{\circ} \mathrm{C}$. 


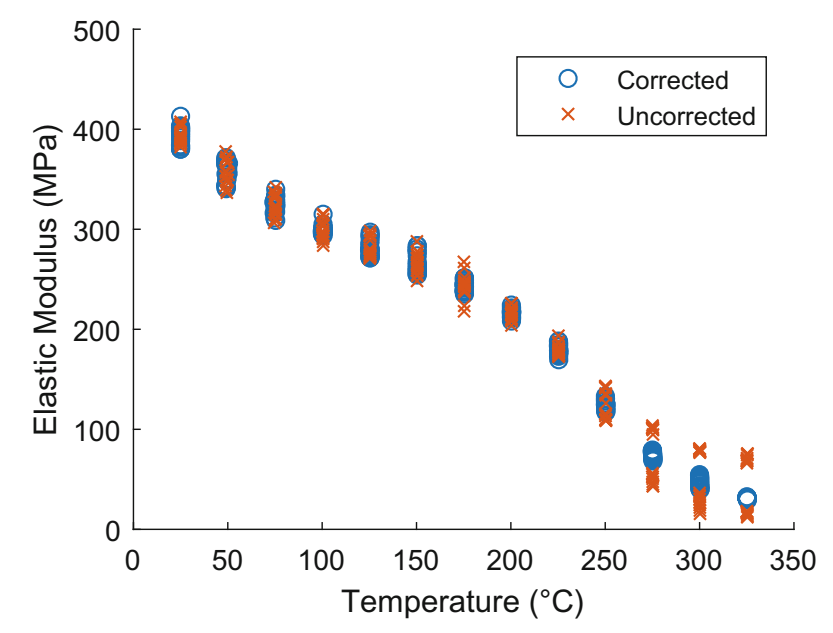

Figure 17. The effect of the shrinkage during the drying on the modulus values collected (specimen ET3).

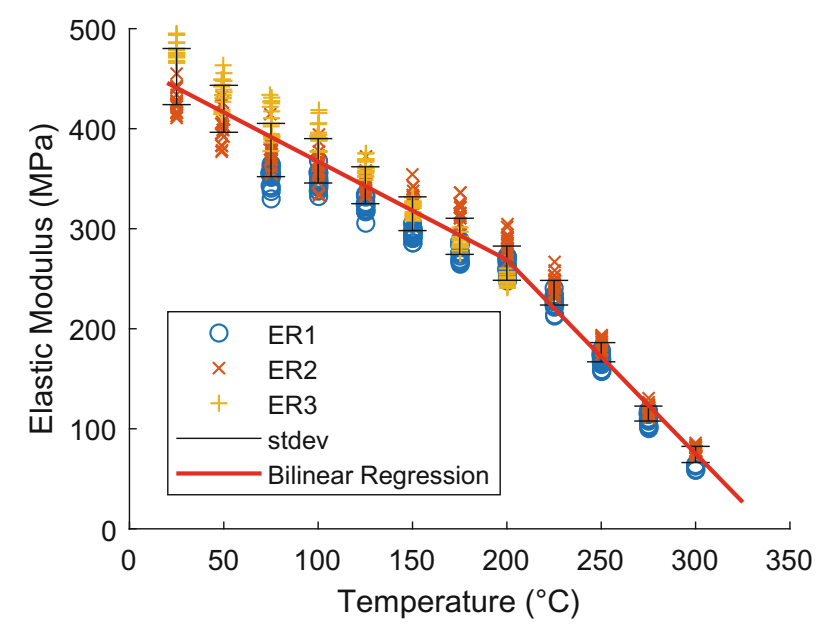

Figure 18. The elastic modulus in the $R$ direction after shrinkage correction measured from three samples indicates very good repeatability.

asymptotically. Combined with the pull-and-release cycle, the resulting curve becomes similar to that of creep, which slowly vanishes after few loading cycles.

Thirdly, as shown in Fig. 16b, elastic modulus increases over time as pyrolysis progresses. It is therefore postulated that this phenomenon may introduce a potential measurement artefact due to pyrolysis at transient state. A sample which has not reached a constant height at the temperature of measurement, meaning, 


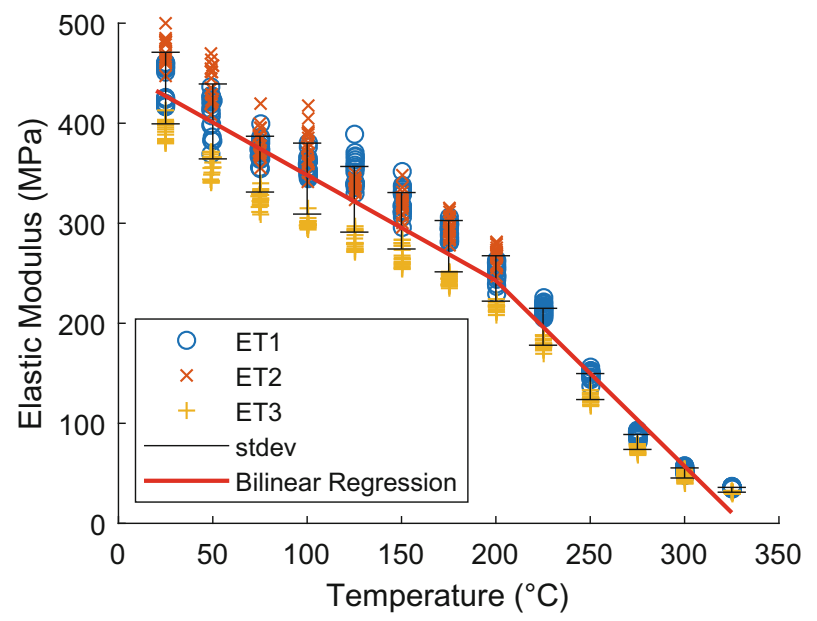

Figure 19. The elastic modulus in the $\mathbf{T}$ direction after shrinkage correction measured from three samples indicates very good repeatability.

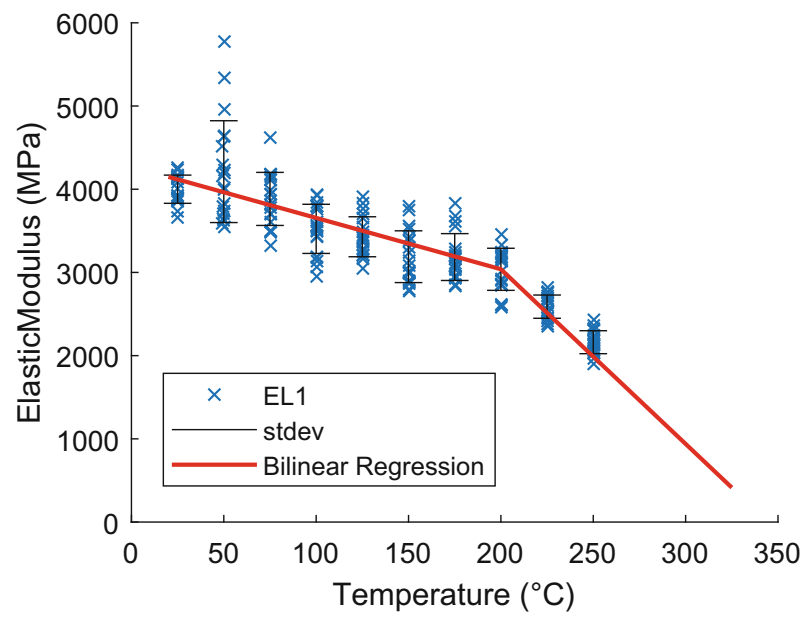

\section{Figure 20. One set of elastic modulus in the $L$ direction requires} several tries and scattered result.

did not undergo the pyrolysis at the temperature may be resulting in lower moduli reading than the sample which underwent the pyrolysis at the set temperature. This can explain why the tests reported in the literature [4-9], and especially the tests performed on the larger specimen of the wood used in hereby research project $(20 \times 7 \mathrm{~mm})$ [17], result in larger decrease of moduli with temperature and why the significant standard deviation is observed. The effect may be coming from 


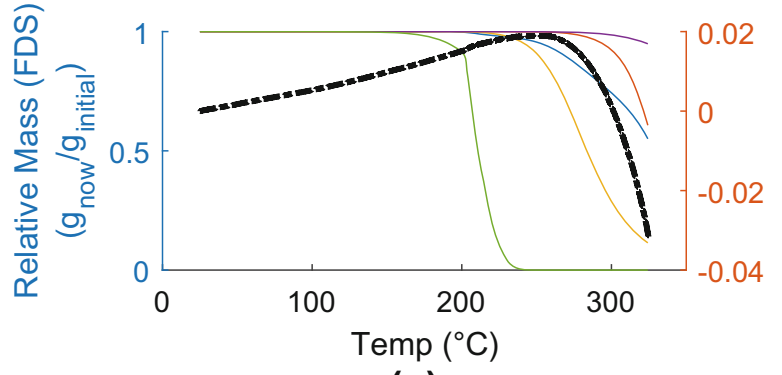

(a)

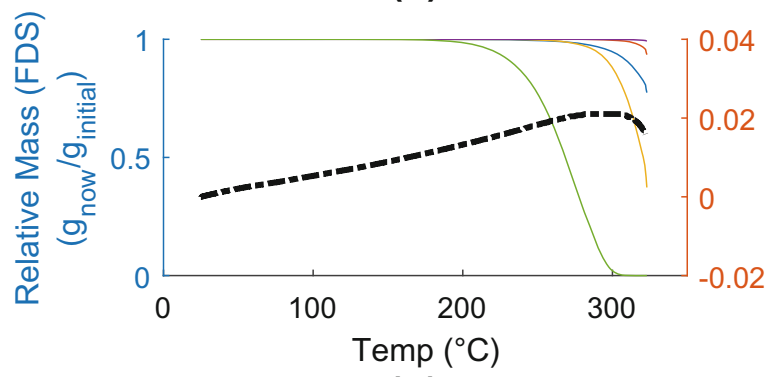

(b)

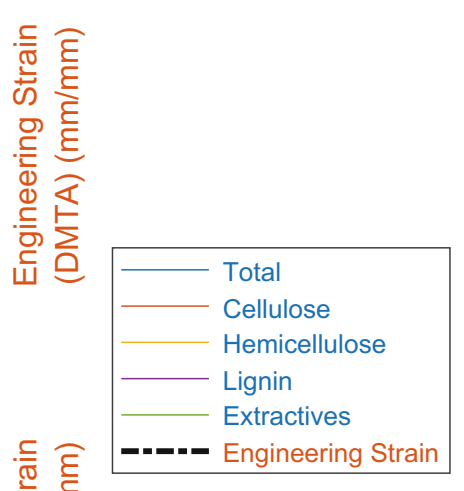

\section{Figure 21. Simulated mass loss rate of Norway spruce wood under 7 to $1^{\circ} \mathrm{C} / \mathrm{min}$ (SR1-7) (a) and "fast" (SRFast) (b) heating rates and contribution by each primary component.}

the combination of shrinkage induced forces due to pyrolysis with tensile stress applied to sample (Fig. 17).

The sample shrinks at high temperatures as is established during the expansion coefficient experiment. During the release, the increase of the normal force reading causes a curve to emulate the creep like behaviour. However, the pyrolysis at given isothermal conditions proceeds only as long as the substrate for the pyrolysis reaction is present. Lignin, hemicellulose and cellulose are postulated to pyrolyze at different temperatures and with different kinetics (see e.g. [30-33]. When the component is fully pyrolyzed, theoretically the sample would achieve the state in which classical elastic modulus could be measured. If the measurement is conducted too early and the samples was not allowed to fully undergo the pyrolysis at considered temperature, the changes in modulus over time are observable. As the sample shrinks, given non-restrained conditions, the elastic modulus increases over time asymptotically (see Fig. 16b).

The elastic moduli of the wood up to $325^{\circ} \mathrm{C}$ was established with the developed methodology for R, T, and L directions, presented in Figs. 18, 19, 20. Scatter of the elastic moduli data from 3 measurements is within $10.9 \%$ and $10.3 \%$ for $\mathrm{R}$ and $\mathrm{T}$ directions respectively, suggesting good repeatability. However, the L direction from one measurement shows significantly lower elastic modulus value compared to e.g. [1, 17], while scatter is within $14.6 \%$. 
Several reasons may contribute to the less reliable measurement of $\mathrm{L}$ direction. Firstly, during the pull-and-release cycle, the stiffer response results in an order of magnitude less displacement, reducing the measurement accuracy. Secondly, the $\mathrm{SRF}$ clamps compresses $\mathrm{L}$ specimens in $\mathrm{R}$ or $\mathrm{T}$ direction, as opposed to $\mathrm{R}$ or $\mathrm{T}$ specimens being compressed in $\mathrm{L}$ direction. The significantly less compressive strength reduces the allowable tensile force before clamp slipping occurs. Further optimisation of the L specimen is necessary in future studies with similar equipment. Nonetheless, in the data presented by Kuronen [17] for elastic moduli at $250^{\circ} \mathrm{C}$ the scatter was within $\pm 66 \%$ to the average. For that reason, the hereby presented methodology seems to produce relatively small standard deviations.

It seems, that in fact, the shape of the curve reminisces the exponential decay above $200^{\circ} \mathrm{C}$ or the whole curve follows rather logarithmic trend as was postulated by Lie [34], than a straight line. However, above $250^{\circ} \mathrm{C}$ the reading of $\mathrm{E}$ depended on the pull or release mode. The question on the differences between modulus values in tension or compression are still opened if the values recorded from pull and release can be so drastically different. For the simplicity of input into the $\mu \mathrm{FEM}$ simulations, the straight line below and above $200^{\circ} \mathrm{C}$ were fitted into obtained data, which is consistent with Eurocode [10] suggestions and in line with multiple previous publications [4]. Nevertheless, it is underlined hereby that the relationship is most likely not linear.

\subsection{FDS Simulation}

FDS simulations of SR7-1 and SRFast specimens are presented in Fig. 21. At temperature above $200^{\circ} \mathrm{C}$ where shrinkage occurs, specimen SR7-1 has the slowest heating rate, while SRFast is the fastest. Consequently, to reach $325^{\circ} \mathrm{C}$, specimen SR7-1 takes the longest. The longer heating period results in more prominent shrinkage by SR7-1 compared to SRFast, as shown in Fig. 21a and b respectively as dashed thick lines. This observation is in agreement with FDS simulation results presented as coloured regular lines in the same figure, where the slower heating rate leads to more mass loss of primary chemical components.

However, when heated at a constant temperature, pyrolysis reaction goes towards a certain asymptotic equilibrium [11]. Further pyrolysis continues when temperature is increased into another constant value. This is similar to the heating profile of the moduli program, as depicted in Fig. 11. The process of approaching asymptotic equilibrium is clearly shown in Fig. 22c, most prominently at temperatures of $275^{\circ} \mathrm{C}$ and $300^{\circ} \mathrm{C}$, where mass loss rate gradually declines towards zero only to increase again at a new constant temperature. The effect is also reflected by the displacement plot from DMTA reading, but only taken at tension level of $0.72 \mathrm{~N} .^{2}$ At such constant force, constant temperature of $275^{\circ} \mathrm{C}$ results in a shrinkage which rate slows down gradually, only to suddenly accelerate again at new temperature of $300^{\circ} \mathrm{C}$, followed by the same slow-down pattern. This phenomenon is aligned with the observation of isothermic TGA by Grioui et al. [16].

\footnotetext{
${ }^{2}$ Tensile force of $0.72 \mathrm{~N}$ is tested to yield the most points for ER2 specimen discussed here.
} 


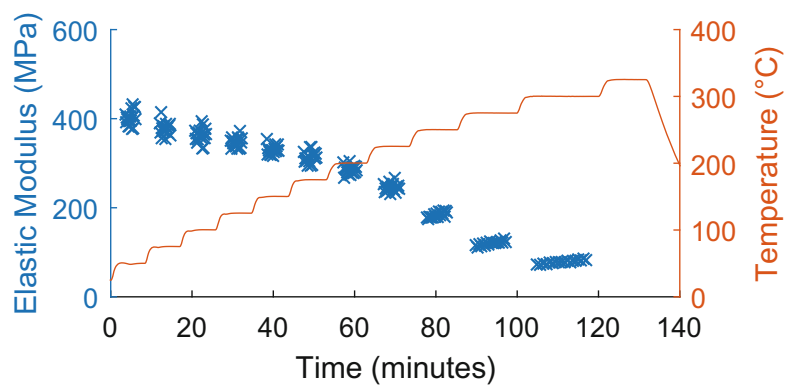

(a)

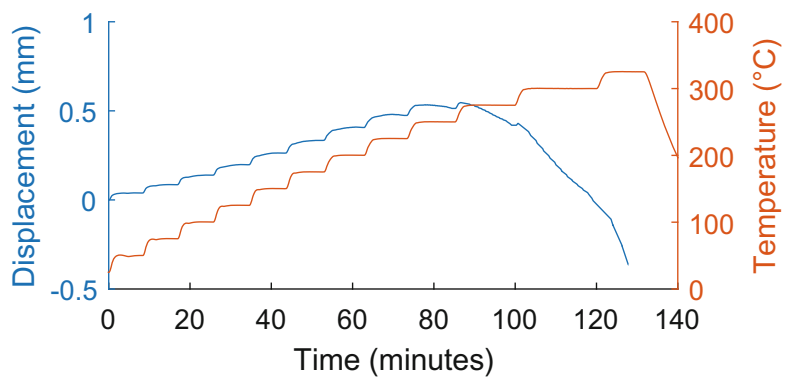

(b)

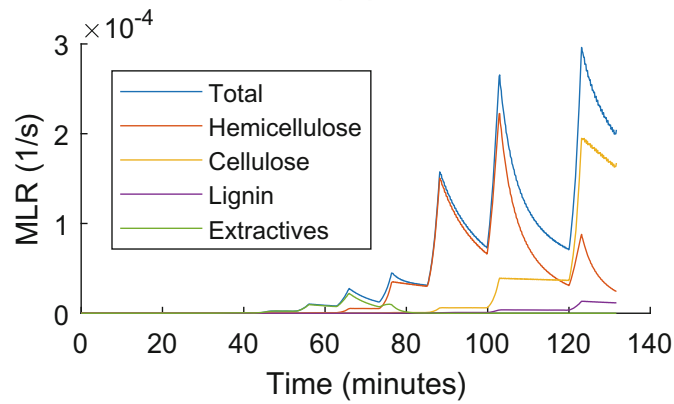

(c)

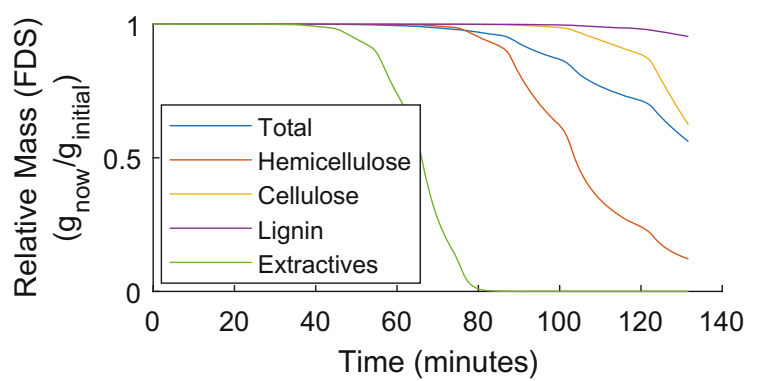

(d) 


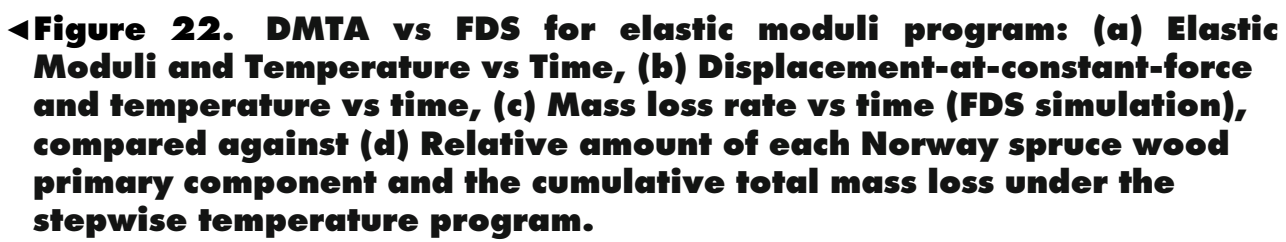

As was discussed before, the discussion in the literature on the shape of the curve describing the relationship between elastic modulus and temperature was not conclusive [4]. Part of the researchers assumes the linear decrease of modulus from room temperature to $300^{\circ} \mathrm{C}$, part assumes that there are two linear relationships, one up to $200^{\circ} \mathrm{C}$ and one above $200^{\circ} \mathrm{C}$, while part of the researchers support the assumption that the modulus decreases above $200^{\circ}$ but not in a linear way [4]. Comparison of the experimentally obtained data hereby of the elastic modulus indicates the non-linear decrease. The supplementation of the experimental data with the pyrolysis reaction modelling by FDS suggests that the mass loss associated with loss of extractives and hemicellulose is responsible for the decrease of elastic modulus, while the decomposition of cellulose appear to correlate with rapid shrinkage at high temperature. Lignin loss is seemingly not contributing to the loss of this mechanical property. This information may be used in the future to study the degradation of other mechanical properties of wood such as strength and durability after fire by analysis of its chemical composition.

\section{Conclusions}

The methodologies to determine the elastic moduli, as well as the thermal expansion coefficients, of the wood samples in the temperature range up to $325^{\circ} \mathrm{C}$ in $\mathrm{R}$ and $\mathrm{T}$ direction were developed for small wood samples. A novel drying method was proposed, eliminating the possibility of moisture reabsorbtion from exposure to ambient air during transport or attachment process. Finite difference simulation proved the specimens adequately thin to avoid significant temperature variation within the specimen. The measurements were conducted on wood samples with assumed $0 \%$ moisture content, assured by the lack of changes in the dimensions during the exposure to drying gases. The reliability of the data was high as the repeatability of the test was on the level of $10.9 \%$ and $10.3 \%$ respectively.

Measurement in $\mathrm{L}$ direction is also conducted, though the scatter was on the significantly-higher level of $14.6 \%$, with measured elastic moduli significantly lower than those from literatures. Several problems may contribute towards the unreliable results obtained in longitudinal direction, namely the significantly reduced accuracy due to stiffer specimen and reduced clamping force due to fixture clamps compression in the weaker transverse direction. This aspect of the study is still open for improvements in future research.

The thermal expansion coefficients in the $\mathrm{R}$ and $\mathrm{T}$ directions follow a mostly linear trend until the onset of pyrolysis. However, in $\mathrm{T}$ direction the thermal 
expansion experience reduced rate between 50 and $100^{\circ} \mathrm{C}$. The behaviour is replicable given different heating rates, concluding that the phenomena is not time-dependent. Thermal expansion coefficients can be calculated from within the range of 25 to $200^{\circ} \mathrm{C}$, presented in Table 4 . Above the $250^{\circ} \mathrm{C}$ the shrinkage is observed in the sample. The shrinkage is dependent on the rate of the heating indicating that kinetics of reaction governs the moduli value, causing it to be time dependent. This conclusion is also supported by FDS simulations of the same temperature histories. In fact, the unrestricted specimen increases its modulus over time at certain temperature when kept in isothermal conditions as the sample shrinks.

Prior to this research no consensus was found on the shape of the relationship between elastic moduli and temperature. As a result of our observation, calculations and literature analysis of available data the elastic moduli of wood in the pyrolytic conditions measured at certain temperature is dependent on:

- The temperature

- The size of the sample

- The time of conditioning of the sample at studied temperature.

Supplementing the experimental results with FDS simulations of pyrolysis indicate that the loss of the modulus follows the onset of hemicellulose decomposition and onwards. The simulations also indicate that the decomposition of cellulose closely correlates to pyrolysis shrinkage.

Such combination of experimental and numerical methods appears to be an effective approach to linking the evolution of wood primary chemical component degradations under fire conditions to mechanical changes. Suggestion for future research is to study the effect on other parameters (e.g. strength and durability), and possibly at higher temperatures.

\section{Acknowledgements}

This work was supported by the Academy of Finland (Grant Number 297030). The authors highly appreciate the discussions with Prof. Wojciech Sołowski and Dr. Djebar Baroudi during the experimental method development.

\section{Author's Contributions}

S.F. and S.H. encouraged T.A. and M.M. to conduct experiments measuring relationship between elastic modulus, expansion, shrinkage, and temperature for different orthotropic directions. Results of this study would provide data to another study by S.F. in micro-FEM simulation of wood cells. T.A. and M.M. developed the experimental method. T.A. developed the detailed procedure, conducted the measurements (except for elastic modulus vs lift velocity by M.M.), and analysed the data, while M.M. provided supervision. T.A. conducted the Finite-DifferenceMethod simulation to quantify the suitability of specimen dimensions and heating rates. T.A., M.M., and S.F. continuously discussed the experimental results. 
A.RP. conducted the Fire-Dynamics-Simulator (FDS) simulation. T.A. and M.M. wrote the manuscript, with the exception of "FDS simulation" subsection written by A.RP. T.A. provided the schematics, pictures, and graphs, with advices from M.M. S.H. provided funding for the study, overall supervision, and inputs on the manuscript.FundingOpen access funding provided by Aalto University. This work was supported by the Academy of Finland (Grant Number 297030).Data Availabilityhttps://doi.org/10.5281/zenodo.4003429 (open access).Code Availabilityhttp s://doi.org/10.5281/zenodo.4003429 (open access).

\section{Declarations}

Conflicts of interest The authors declare that they have no known competing financial interests or personal relationships that could have appeared to influence the work reported in this paper.

\section{Open Access}

This article is licensed under a Creative Commons Attribution 4.0 International License, which permits use, sharing, adaptation, distribution and reproduction in any medium or format, as long as you give appropriate credit to the original author(s) and the source, provide a link to the Creative Commons licence, and indicate if changes were made. The images or other third party material in this article are included in the article's Creative Commons licence, unless indicated otherwise in a credit line to the material. If material is not included in the article's Creative Commons licence and your intended use is not permitted by statutory regulation or exceeds the permitted use, you will need to obtain permission directly from the copyright holder. To view a copy of this licence, visit http://creat ivecommons.org/licenses/by/4.0/.

\section{Appendix A: Temperature Distribution Calculation with FDM}

In the previous stage of the project, the samples of the size $20 \times 7 \mathrm{~mm}$ were tested initially at $20^{\circ} \mathrm{C} / \mathrm{min}$ [17]. The literature often reports tests performed on samples with the cross section of $0.39 \times 0.39$ inch $(10 \times 10 \mathrm{~mm})$ [3]. The effect of the sample size on the temperature gradient within the tested specimen was investigated using the Finite Difference Method (FDM), to assure if significantly homogenous temperature distribution can be achieved for this geometry $[3,8,23-$ 27]. Trials-and-errors and consideration of various aspects, including the finite difference simulation, concluded $1 \mathrm{~mm}$ as the ideal thickness to go along with specimen width of $1 \mathrm{~cm}$ and length of $4 \mathrm{~cm}$.

Calculations and results presented in this "Appendix" focus on the final iteration of $1 \mathrm{~mm}$-thick specimen with $2^{\circ} \mathrm{C} / \mathrm{min}$ heating rate, while a hypothetical case of $15 \mathrm{~mm}$-thick specimen with $15^{\circ} \mathrm{C} / \mathrm{min}$ heating rate acts as a comparison. MATLAB code of the finite difference simulation is included in [22]. 


\section{Formulation}

Transient temperature distribution throughout specimen thickness follows 1D heat conduction equation:

$$
\frac{\partial}{\partial t}(u(x, t))=\alpha \frac{\partial^{2}}{\partial x^{2}}(u(x, t)) ; \text { where } \alpha=\frac{k}{c \rho}
$$

where $u=$ temperature, $t=$ time, $x=$ position throughout specimen thickness, $k=$ thermal conductivity, $c=$ heat capacity, and $\rho=$ density.

Temperature distribution for any time is approximated using finite difference with Euler forward time integration:

$$
u(x, t+\Delta t)=u(x, t)+\alpha\left(\frac{u(x+\Delta x, t)+u(x-\Delta x, t)-2 u(x, t)}{\Delta x^{2}}\right) \Delta t
$$

With the following boundary conditions:

$$
\begin{aligned}
& u(x, t=0)=T_{0} \\
& u(x=0, t)=u(x=d, t)=T_{0}+\dot{T} t
\end{aligned}
$$

where $T_{0}=$ initial temperature, $\dot{T}=$ heating rate, and $d=$ specimen thickness.

The elevated temperature results in thermal expansion and reduced elastic modulus in a linear fashion.

$$
\begin{aligned}
& \varepsilon_{\text {Thermal }}(x, t)=\left(u(x, t)-T_{0}\right) \tilde{\alpha} \\
& E(x, t)=E_{0}-\left(u(x, t)-T_{0}\right) C
\end{aligned}
$$

where $\varepsilon_{\text {Thermal }}=$ thermal expansion strain, $\tilde{\alpha}=$ thermal expansion coefficient, $E_{0}=$ initial elastic modulus, and $C=$ elastic modulus reduction rate.

For the mechanisms considered in this model, strains are identified as follows:

$$
\begin{aligned}
& \varepsilon_{\text {total }}=\varepsilon_{\text {elastic }}+\varepsilon_{\text {thermal }} \\
& \Rightarrow \varepsilon_{\text {elastic }}=\varepsilon_{\text {total }}-\varepsilon_{\text {thermal }}
\end{aligned}
$$

The specimen is clamped, thus $\varepsilon_{\text {total }}$ is not a function of $x$.

$$
\varepsilon_{\text {elastic }}(x, t)=\varepsilon_{\text {total }}(t)-\varepsilon_{\text {thermal }}(x, t)
$$

When the specimen is tensioned, elastic deformation occurs: 


$$
\begin{aligned}
& \Sigma F=w \int_{0}^{d} E(x, t) \varepsilon_{\text {elastic }}(x, t) d x-F_{\text {tension }} \\
& =w \int_{0}^{d} E(x, t)\left(\varepsilon_{\text {total }}(t)-\varepsilon_{\text {thermal }}(x, t)\right) d x-F_{\text {tension }}=0 \\
& \Rightarrow \varepsilon_{\text {total }}(t)=\frac{\frac{F_{\text {tensile }}}{w}+\int_{0}^{d} E(x, t) \varepsilon_{\text {therm }}(x, t) d x}{\int_{0}^{d} E(x, t) d x}
\end{aligned}
$$

The apparent thermal expansion $\varepsilon_{\text {thermal,apparent }}(t)$ during experiment is therefore:

$$
\begin{aligned}
& \varepsilon_{\text {thermal,apparent }}(t)=\varepsilon_{\text {total }}(t)-\varepsilon_{\text {initial }}=\frac{\frac{F_{\text {tensile }}}{w}+\int_{0}^{d} E(x, t) \varepsilon_{\text {therm }}(x, t) d x}{\int_{0}^{d} E(x, t) d x}-\frac{F_{\text {tensile }}}{E_{0} w d} \\
& \Rightarrow \varepsilon_{\text {thermal,apparent }}(t)=\frac{\frac{F_{\text {tensile }}}{w}+\int_{0}^{d}\left(E_{0}-\left(u(x, t)-T_{0}\right) C\right)\left(u(x, t)-T_{0}\right) \tilde{\alpha} d x}{\int_{0}^{d}\left(E_{0}-\left(u(x, t)-T_{0}\right) C\right) d x}-\frac{F_{\text {tensile }}}{E_{0} w d}
\end{aligned}
$$

where $u(x, t)$ is acquired from the FDM simulation. Since the transient temperature field $u(x, t)$ is discretized, integrations in equation are carried out numerically.

The apparent thermal expansion $\varepsilon_{\text {thermal,apparent }}(t)$ is the thermal expansion that the equipment detects. However, the theoretical value should be:

$$
\varepsilon_{\text {thermal,theoretical }}(t)=\tilde{\alpha}\left(T(t)-T_{0}\right)=\tilde{\alpha} \dot{T} t
$$

Error is presented as the relative difference between apparent thermal expansion and the theoretical value at the end of the simulation:

$$
\text { Error }=\frac{\varepsilon_{\text {thermal,apparent }}\left(t_{\mathrm{f}}\right)-\varepsilon_{\text {thermal,theoretical }}\left(t_{\mathrm{f}}\right)}{\varepsilon_{\text {thermal,theoretical }}\left(t_{\mathrm{f}}\right)}
$$

where $t_{\mathrm{f}}$ is the time at the end of simulation.

\section{Results}

For the first case, let us define the following parameters for $15 \mathrm{~mm}$ thickness and $15^{\circ} \mathrm{C} / \mathrm{min}$ heating rate:

$$
T_{0}=25^{\circ} \mathrm{C} ; \dot{T}=15^{\circ} \mathrm{C} / \mathrm{min}=0.25^{\circ} \mathrm{C} / \mathrm{s} ; d=15 \mathrm{~mm}=0.015 \mathrm{~m}
$$

While for the second case, we use the following 


$$
T_{0}=25^{\circ} \mathrm{C} ; \dot{T}=2^{\circ} \mathrm{C} / \min =0.0333^{\circ} \mathrm{C} / \mathrm{s} ; d=1 \mathrm{~mm}=0.001 \mathrm{~m}
$$

Other parameters are taken from [35-38] as follows:

$$
\begin{aligned}
& \rho=425 \mathrm{kgm}^{-3} \\
& c=1114+4.86 T \mathrm{Jkg}^{-1} \mathrm{~K}^{-1}\left(T \text { in }{ }^{\circ} \mathrm{C}\right) ; \\
& \kappa=0.1820385\left(1+0.002\left(T-T_{0}\right)\right) \mathrm{Wm}^{-1} \mathrm{~K}
\end{aligned}
$$

where $\rho=$ density (dry), $c=$ specific heat capacity, and $\kappa=$ thermal conductivity.

Solving Eqs. 5-7 with parameters from Eqs. 19 and 21 for the first case, and 20 and 21 for the second case, results in temperature field shown in Fig. 23. The difference between maximum and minimum temperature throughout sample thickness is shown in Fig. 24, with the resulting error in thermal expansion strain measurement in Fig. 25. The second case lacks significant temperature variation, therefore difficult to identify visually from the surface plot. On the other hand, the first case show substantial variation of temperature resembling a parabolic shape, which is the chosen function to approximate temperature distribution in the analytical approximation described in [20]. The FDM simulation predicts $9.41 \%$ thermal expansion strain measurement error for the first case and $3.17 \%$ for the second case.

Continuing from the example described in Eq. 21, let us take the following quantities [39]:

$$
E_{0}=820 \mathrm{MPa}=820 \times 10^{6} \mathrm{~Pa} ; C=\frac{820 \times 10^{6}}{275} \mathrm{~Pa} \mathrm{~K}^{-1} ; \tilde{\alpha}=2.7920 \times 10^{-5}
$$

The resulting apparent thermal expansion strains are shown in Fig. 25.

\section{Appendix B: Shrinkage Correction}

At high temperature, significant shrinkage due to pyrolysis interferes with elastic modulus measurement. As the shrinkage is unavoidable above $250^{\circ} \mathrm{C}$, we propose a method to predict shrinkage strain from the load and displacement history during pull-release cycle. This shrinkage strain is then subtracted from the total strain recorded as displacement by the DMTA. Figure 26 shows typical load and displacement history of pull-release cycle without shrinkage, while Fig. 27 shows a significant shrinkage at high temperature. Shrinkage can also be detected by having load-displacement curve drifting towards a certain direction, as Fig. 28 shows.

First, let us define the components of strain observed in this experiment:

$$
\varepsilon=\varepsilon_{\text {elastic }}+\varepsilon_{\text {pyrolysis }}+\varepsilon_{\text {thermalexpansion }}
$$



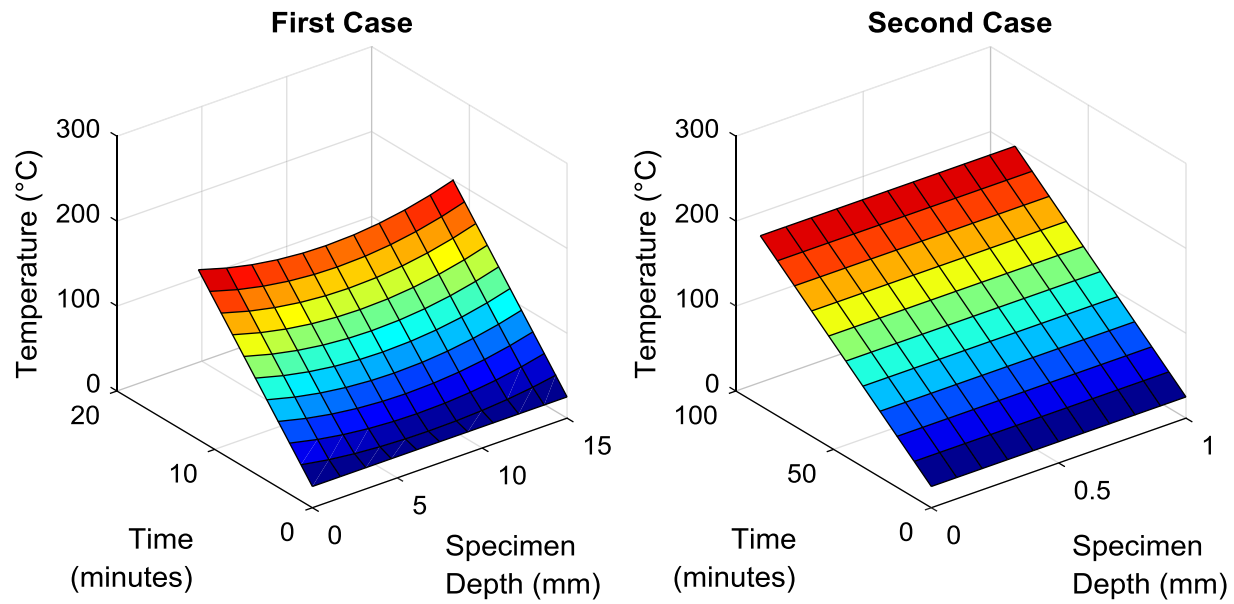

Figure 23. FDM simulation results of temperature field development throughout specimen thickness for both the first $\left(15 \mathrm{~mm}, 15^{\circ} \mathrm{C} / \mathrm{min}\right.$ heating rate) and second (1 $\mathrm{mm}, 2^{\circ} \mathrm{C} / \mathrm{min}$ heating rate) cases.

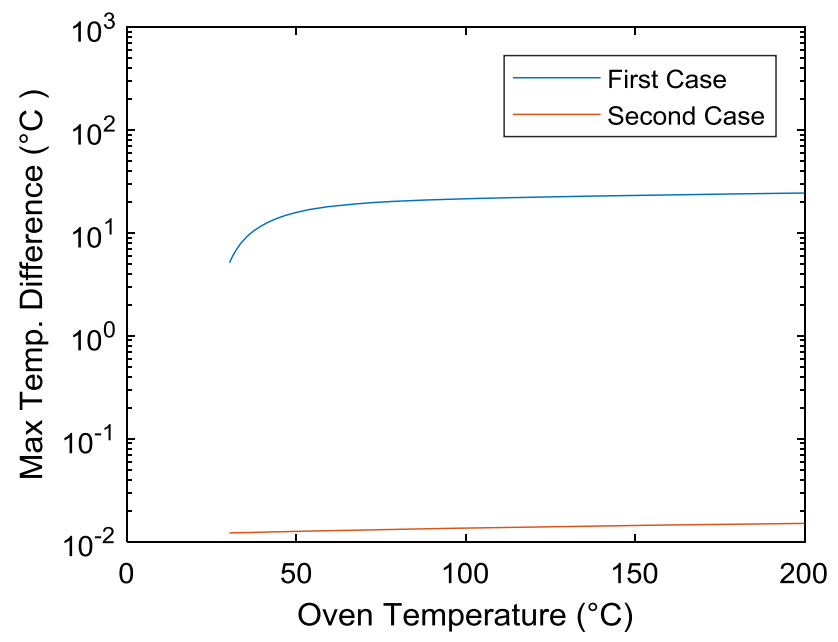

Figure 24. Difference between minimum and maximum temperałure throughout specimen thickness at given oven temperature above $30^{\circ} \mathrm{C}$ for both the first $\left(15 \mathrm{~mm}, 15^{\circ} \mathrm{C} / \mathrm{min}\right)$ and second $\left(1 \mathrm{~mm}, 2^{\circ} \mathrm{C}\right.$ / min heating rate) cases.

The change of strain is therefore:

$$
\Delta \varepsilon=\Delta \varepsilon_{\text {elastic }}+\Delta \varepsilon_{\text {pyrolysis }}+\Delta \varepsilon_{\text {thermal expansion }}
$$




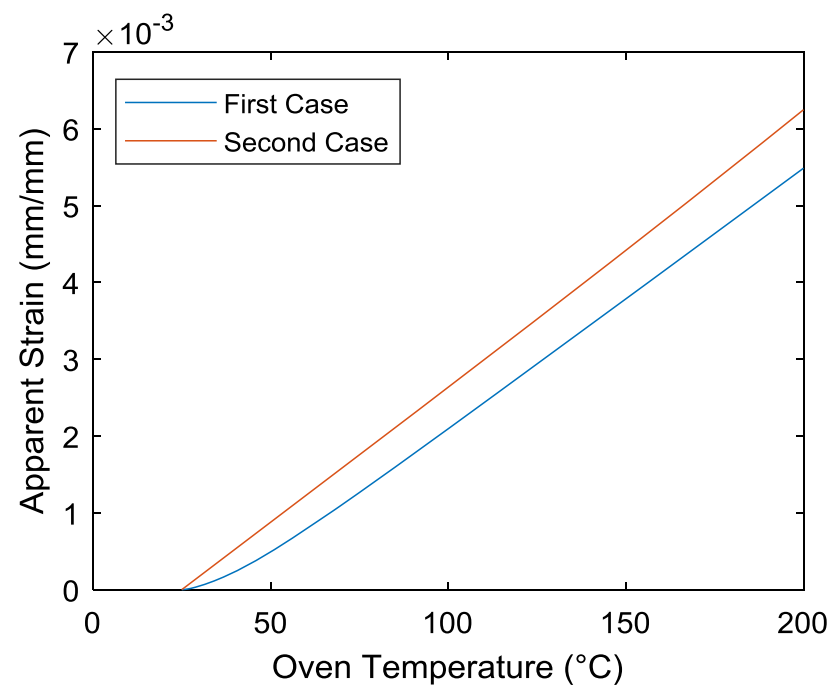

Figure 25. Example of apparent thermal expansion strain for first ( $15 \mathrm{~mm}, 15^{\circ} \mathrm{C} / \mathrm{min}$ ) and second (1 $\mathrm{mm}, 2^{\circ} \mathrm{C} / \mathrm{min}$ heating rate) cases.

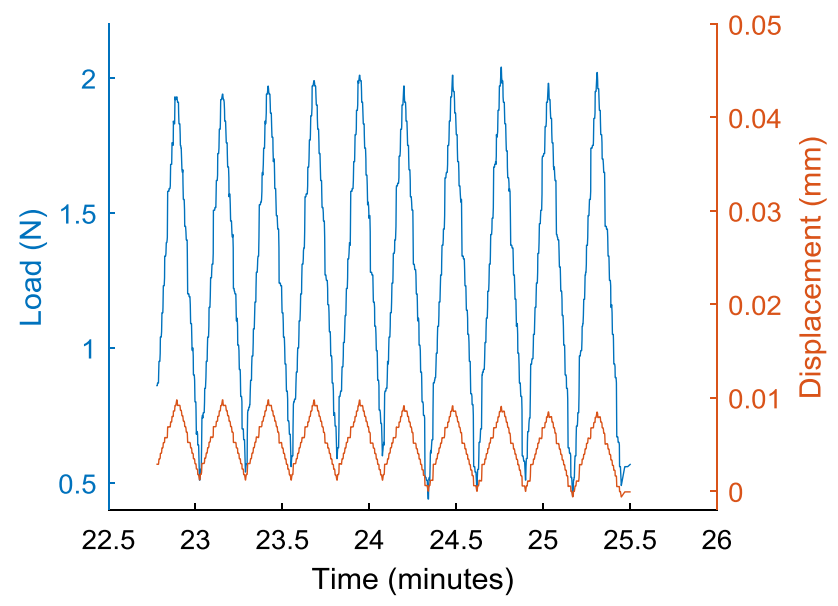

Figure 26. The load-displacement over time at room temperature following initial drying step.

Shrinkage correction procedure applies at constant temperature. Figuress 29, 30 illustrate the shrinkage correction procedure with pull-release cycles at a constant temperature of $300^{\circ} \mathrm{C}$. With a constant temperature, $\Delta \varepsilon_{\text {thermal expansion }}$ vanishes from Eq. 24, therefore:

$$
\Delta \varepsilon=\Delta \varepsilon_{\text {elastic }}+\Delta \varepsilon_{\text {pyrolysis }}
$$




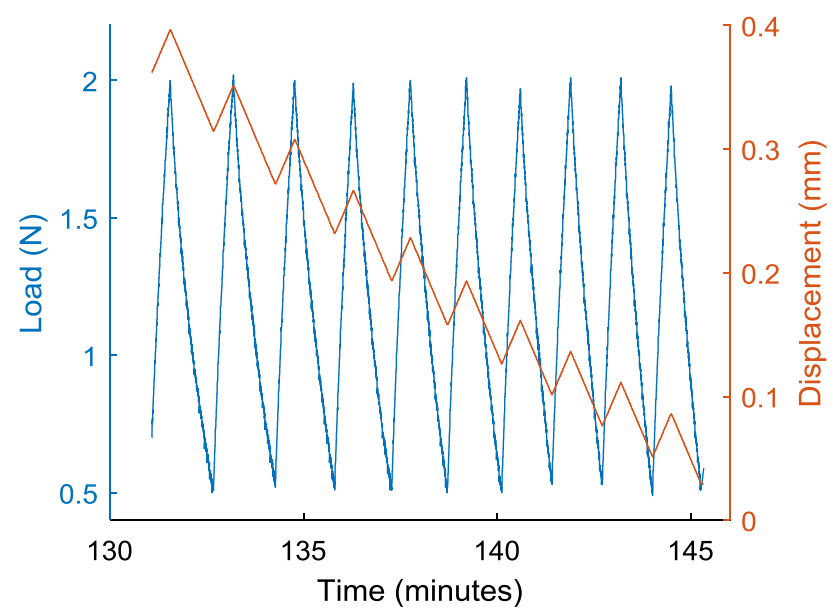

Figure 27. The load-displacement over time at temperature of $300^{\circ} \mathrm{C}$ over time.

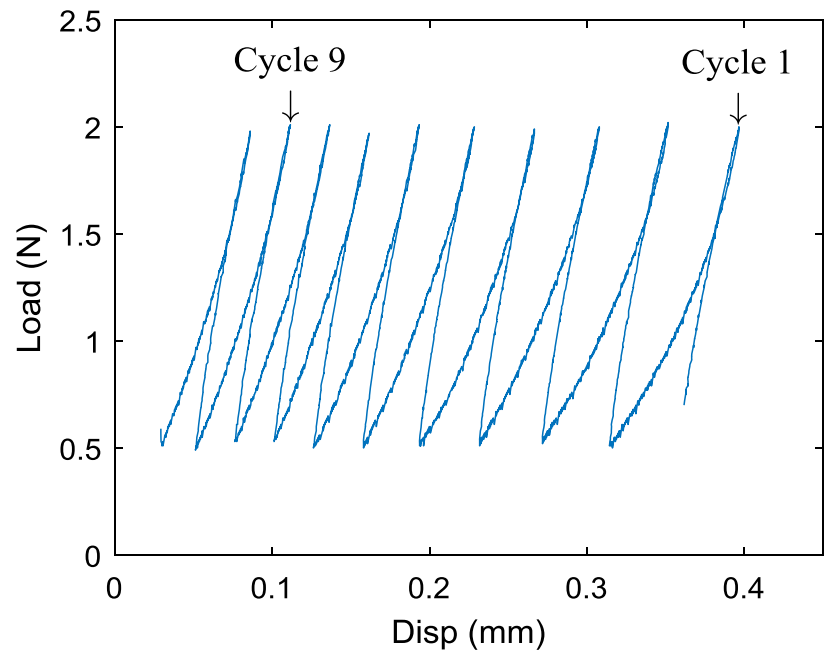

Figure 28. Load-displacement curve at temperature of $300^{\circ} \mathrm{C}$ over time.

Points $\left(t_{0}, \varepsilon_{0}\right)$ and $\left(t_{1}, \varepsilon_{1}\right)$ are both at the same level of tensile force, therefore only $\Delta \varepsilon_{\text {pyrolysis }}$ contributes to the difference in total strain. The shrinkage correction method uses this difference to predict a constant $d \varepsilon_{\text {pyrolysis }} / d t$ between $t_{0}$ and $t_{1}$.

$$
\frac{d \varepsilon_{\text {pyrolysis }}}{d t}=\dot{\varepsilon}_{\text {pyroysis }}=\frac{\varepsilon_{1}-\varepsilon_{0}}{t_{1}-t_{0}}
$$




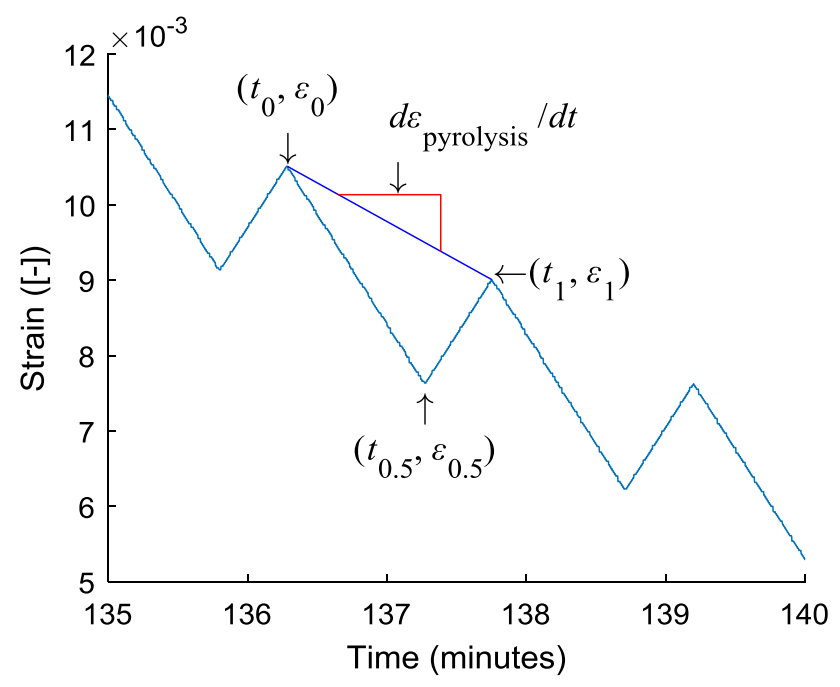

Figure 29. One shrinkage correction procedure (strain plot).

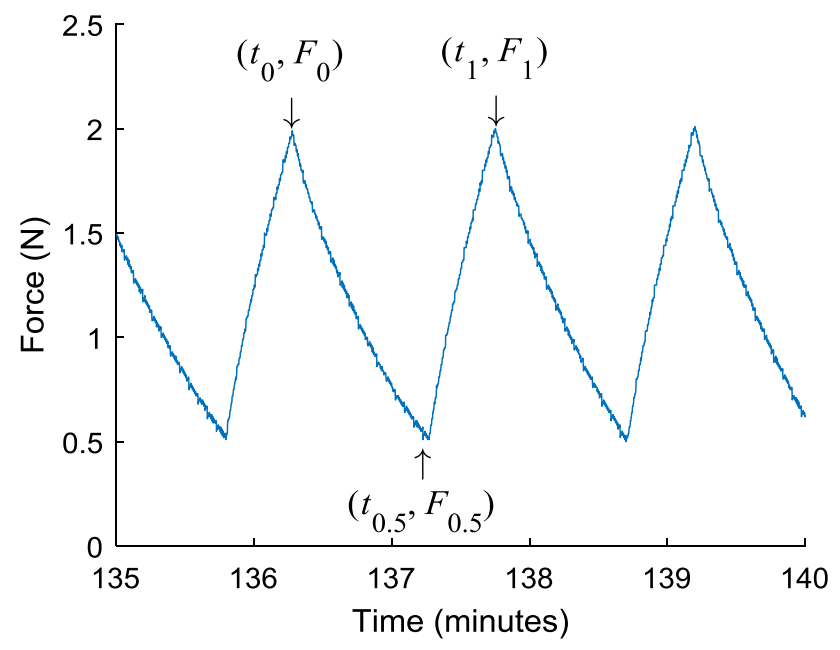

Figure 30. One shrinkage correction procedure (tensile force plot).

Therefore, $\Delta \varepsilon_{\text {pyrolysis }}$ between any two arbitrary points of time between $t_{0}$ and $t_{1}$ is:

$$
\varepsilon_{\text {pyrolysis }}\left(t_{b}\right)-\varepsilon_{\text {pyrolysis }}\left(t_{a}\right)=\left(t_{b}-t_{a}\right) \dot{\varepsilon}_{\text {pyrolysis }} \text { for } t_{0} \leq t_{a} \leq t_{1} \text { and } t_{0} \leq t_{b} \leq t_{1}
$$




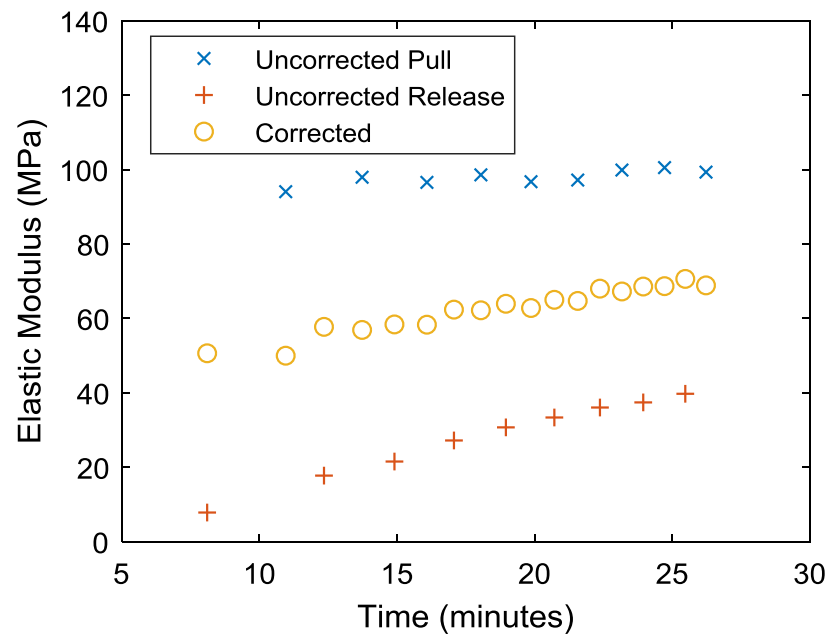

Figure 31. Elastic moduli measurement at $300^{\circ} \mathrm{C}$ with/without correction.

$$
\Delta \varepsilon_{\text {pyrolysis }}=\dot{\dot{\varepsilon}}_{\text {pyrolysis }} \Delta t \text { for } t_{0} \leq t \leq t_{1}
$$

With $\Delta \varepsilon_{\text {pyrolysis }}$ established, extraction of elastic modulus from the DMTA data now becomes possible. Let us first expand $\Delta \varepsilon_{\text {elastic }}$ :

$$
\Delta \varepsilon_{\text {elastic }}=\frac{\Delta F}{E}
$$

Substituting Eqs. 26, 28, and 29 to Eq. 25 results in:

$$
\Delta \varepsilon=\frac{\Delta F}{E}+\dot{\varepsilon}_{\text {pyrolysis }} \Delta t=\frac{\Delta F}{E}+\left(\frac{\varepsilon_{1}-\varepsilon_{0}}{t_{1}-t_{0}}\right) \Delta t
$$

Let us now focus on the release mechanism, i.e. the line connecting points $\left(t_{0}, \varepsilon_{0}\right)$ and $\left(t_{0.5}, \varepsilon_{0.5}\right) . \Delta \varepsilon, \Delta F$, and $\Delta t$ are:

$$
\begin{aligned}
& \Delta \varepsilon=\varepsilon_{0.5}-\varepsilon_{0} \\
& \Delta F=F_{0.5}-F_{0} \\
& \Delta t=t_{0.5}-t_{0}
\end{aligned}
$$

Equation 30 then becomes: 


$$
\begin{aligned}
& \left(\varepsilon_{0.5}-\varepsilon_{0}\right)=\frac{\left(F_{0.5}-F_{0}\right)}{E}+\left(\frac{\varepsilon_{1}-\varepsilon_{0}}{t_{1}-t_{0}}\right)\left(t_{0.5}-t_{0}\right) \\
& \Rightarrow E=\frac{\left(F_{0.5}-F_{0}\right)}{\left(\varepsilon_{0.5}-\varepsilon_{0}\right)-\left(\frac{\varepsilon_{1}-\varepsilon_{0}}{t_{1}-t_{0}}\right)\left(t_{0.5}-t_{0}\right)}=E_{\text {release }}
\end{aligned}
$$

For pull mechanism between points $\left(t_{0.5}, \varepsilon_{0.5}\right)$ and $\left(t_{1}, \varepsilon_{1}\right)$, similar procedure applies. Figure 31 shows an example of uncorrected and corrected elastic modulus data measured at $300{ }^{\circ} \mathrm{C}$.

\section{References}

1. Kretschmann DE (2010) Chapter 05: mechanical properties of wood. In: Wood handbook: wood as an engineering material, vol 190, USDA Forest Service, Forest Products Laboratory, Madison, Wisconsin, pp 5-1-5-46

2. Record SJ (1914) The mechanical properties of wood, including a discussion of the factors affecting the mechanical properties, and methods of timber testing. Wiley, NewYork

3. Gerhards CC (1982) Effect of moisture content and temperature on the mechanical properties of wood: an analysis of immediate effects. Wood Fiber Sci 14(1):4-36

4. Benichou N, Sultan M (1999) Fire resistance of lightweight wood-framed assemblies: state-of-the-art report. Institute for Research in Construction

5. Janssens ML (1997) A method for calculating the fire resistance of exposed timber decks. In: Fire Safety Science - Proceedings of the Fifth International Symposium

6. Thomas GC (1996) Fire resistance of light timber framed walls and floors. PhD Thesis, University of Canterbury, Civil Engineering

7. Lie TT (1992) Structural fire protection. American Society of Civil Engineers, New York

8. Schaffer EL (1972) Elevated temperature effect on the longitudinal mechanical properties of wood. PhD Thesis, The University of Wisconsin - Madison

9. Preusser R (1968) Plastic and elastic behaviour of wood affected by heat in open systems. Holztechnologie 9(4):229-231

10. EN BS (1995) 1-2 Eurocode 5. Design of timber structures. General structural fire design. British Standards Institution

11. Candelier K, Thevenon M-F, Petrissans A, Dumarcay S, Gerardin P, Petrissans M (2016) Control of wood thermal treatment and its effects on decay resistance: a review. Ann For Sci 73(3):571-583

12. Grønli MG, Várhegyi G, Di Blasi C (2002) Thermogravimetric analysis and devolatilization kinetics of wood. Ind Eng Chem Res 41(17):4201-4208

13. Antal MJ (1985) Advances in solar energy. Biomass pyrolysis: a review of the literature Part 2-lignocellulose pyrolysis. Springer, Berlin, pp. 175-255

14. Tran DQ, Rai C (1978) A kinetic model for pyrolysis of Douglas fir bark. Fuel 57(5):293-298

15. Goodrich T, Nawaz N, Feih S, Lattimer BY, Mouritz AP (2010) High-temperature mechanical properties and thermal recovery of balsa wood. J Wood Sci 56(6):437-443 
16. Grioui N, Halouani K, Zoulalian A, Halouani F (2006) Thermogravimetric analysis and kinetics modeling of isothermal carbonization of olive wood in inert atmosphere. Thermochim Acta 440(1):23-30

17. Kuronen H, Mikkola E, Hostikka S (2020) Tensile strength of wood in high temperatures before charring. Fire Mater. https://doi.org/10.1002/fam.2813

18. Rinta-Paavola A, Hostikka S (2021) A model for the pyrolysis of two Nordic structural timbers. Fire Mater. https://doi.org/10.1002/fam.2947

19. Lyon R, Safronava N, Oztekin E (2011) A simple method for determining kinetic parameters for materials in fire models. Fire Saf Sci 10:765-777

20. Lyon RE, Safronava N, Senese J, Stoliarov SI (2012) Thermokinetic model of sample response in nonisothermal analysis. Thermochim Acta 545:82-89

21. Richter F, Atreya A, Kotsovinos P, Rein G (2019) The effect of chemical composition on the charring of wood across scales. Proc Combust Inst 37(3):4053-4061

22. Adibaskoro T, Makowska M, Fortino S, Hostikka S (2021) Experimental data on elastic modulus, thermal expansion, and pyrolysis shrinkage of Norway spruce under high temperature [Raw experimental data and code]. https://doi.org/10.5281/zenodo.4003429

23. Comben A (1964) The effect of low temperatures on the strength and elastic properties of timber. Inst Wood Sci J 13:44-55

24. Ishida S (1954) The effect of temperature on the strength of wood. Hokkaido Univ Res Bull Coll Exp For 17:1-14

25. Noack D, Geissen A (1976) Influence of temperature and moisture on modulus of elasticity in freezing state. Holz als Roh- und Werkstoff 34(2):55-62

26. Sellevold EJ, Radjy F, Hoffmeyer P, Bach L (2007) Low temperature internal friction and dynamic modulus for beach wood. Wood Fiber Sci 7(3):162-169

27. Siimes F (1966) The effect of specific gravity, moisture content, temperature and heating time on the tension and compression strength and elasticity properties perpendicular to the grain of Finnish pine spruce and birch wood and the significance of these factors on the checking of timber at kiln drying. VTT Technical Research Centre of Finland

28. Sjöström E (1981) Wood chemistry: fundamentals and applications. Academic Press Inc, New York

29. Goli G, Becherini F, Di Tuccio MC, Bernardi A, Fioravanti M (2019) Thermal expansion of wood at different equilibrium moisture contents. J Wood Sci 65(1):4

30. Varhegyi G, Antal MJ Jr, Jakab E, Szabó P (1997) Kinetic modeling of biomass pyrolysis. J Anal Appl Pyrol 42(1):73-87

31. Antal MJJ, Varhegyi G (1995) Cellulose pyrolysis kinetics: the current state of knowledge. Ind Eng Chem Res 34(3):703-717

32. Di Blasi C, Lanzetta M (1997) Intrinsic kinetics of isothermal xylan degradation in inert atmosphere. J Anal Appl Pyrol 40:287-303

33. Caballero JA, Font R, Marcilla A, Conesa JA (1995) New kinetic model for thermal decomposition of heterogeneous materials. Ind Eng Chem Res 34(3):806-812

34. LTT (1992) Structural fire protection. In: Manuals and reports on engineering practice, No. 78. American Society of Civil Engineers, New York

35. Dunlap F (1912) The specific heat of wood, 110US Department of Agriculture, Forest Service

36. Kollmann FF, Kuenzi EW, Stamm AJ (2012) Principles of wood science and technology: II Wood based materials. Springer, Berlin

37. Sonderegger W, Hering SP (2011) Thermal behaviour of Norway spruce and European beech in and between the principal anatomical directions. Holzforschung 65(3):369-375

38. Ragland K, Aerts D, Baker A (1991) Properties of wood for combustion analysis. Biores Technol 37(2):161-168 
39. Weatherwax RC, Stamm AJ (1956) The coefficients of thermal expansion of wood and wood products. U.S. Dept. of Agriculture, Forest Service, Forest Products Laboratory, Madison, Wisconsin

Publisher's Note Springer Nature remains neutral with regard to jurisdictional claims in published maps and institutional affiliations. 